\title{
التعاون القضائي الدولي لمكافحة الجريمة المنظمة عبر الوطنية و إشكالياته
}

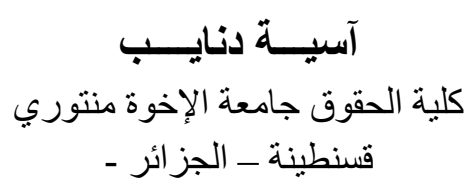

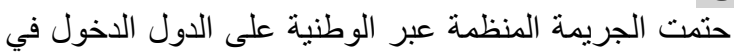

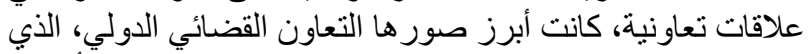

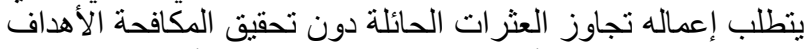

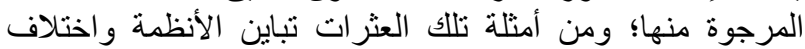

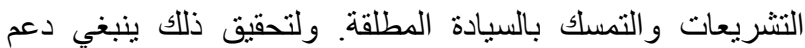

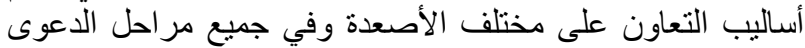

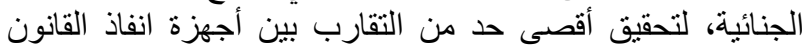

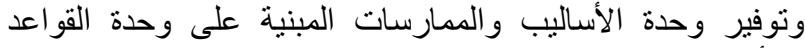
و الأنظمة الإجر ائية و القانونية.

الكلمات المفتاحية : التعاون الدولي، مبدأ السيادة، الجريمة

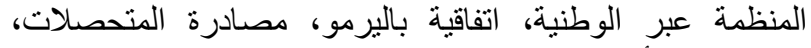
الاعتر اف بالأحكام الجنائية، تسليم المجرمين. 
وتعنى هذه الأوراق البحثية ببحث الإشكالية التالية: ما مدى فعالية أساليب التعاون القضائي الدولي

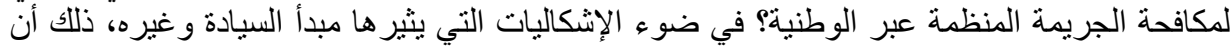

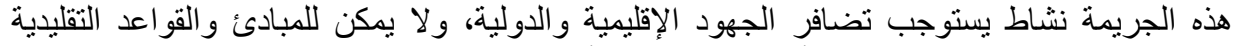

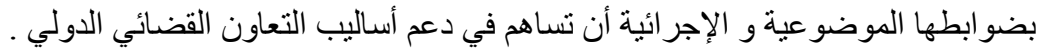

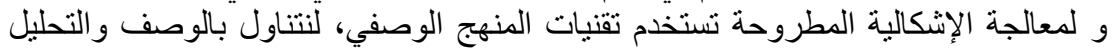

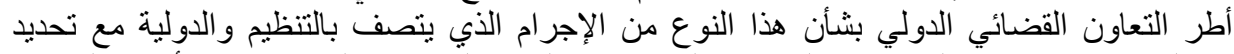

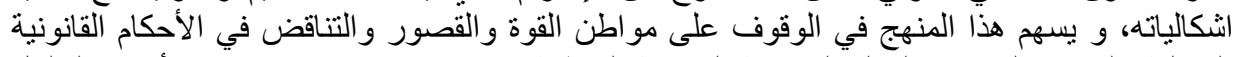

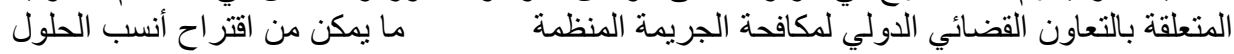

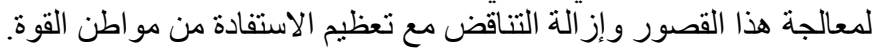

وتقسم المعالجة لجانبين ، المطلب الأول يتناول إجراءات التعاون القضائي الدولي لمكافحة الجريمة المنظمة عبر الوطنية ، ثم المطلب الثاني ويتناول إنكاليات التعاون القضائي التئي الدولي لمكافحة الجريمة المنظمة عبر الوطنية.

\section{المطلب الأول: إجراءات التعاون القضائي الدولي لمكافحة الجريمة المنظمة عبر الوطنية:}

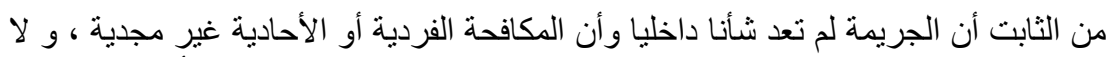

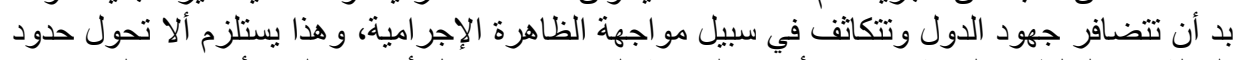

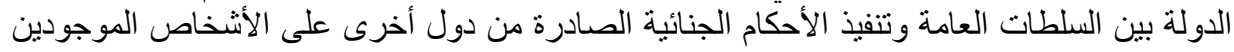

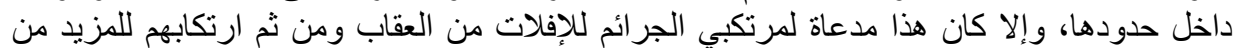

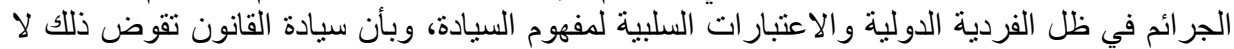

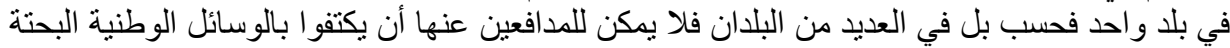

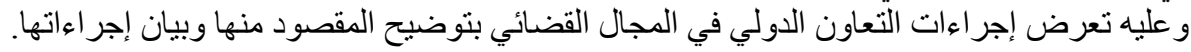

$$
\text { الفقرة الأولى : تعريف التعاون القضائي الدولي الأول: مفهوم التعاون القضائي الدولي }
$$

التعاون هو التضافر المشترك بين شخصين أو أكثر لتحقيق نفع مشترك فالتعاون هو تحرك

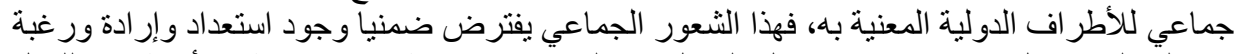

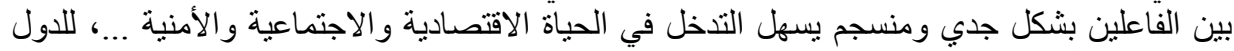

فمفهوم التعاون الدولي مشتق من مفهوم القانون الجنائي الدولي ، حيث عرّفه الأستاذ محمد الأني

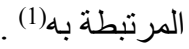

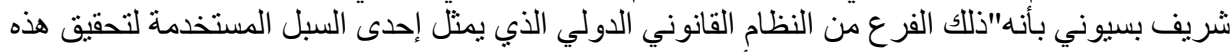

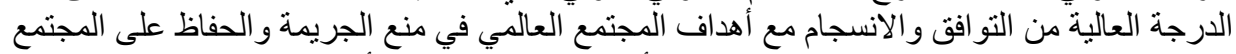

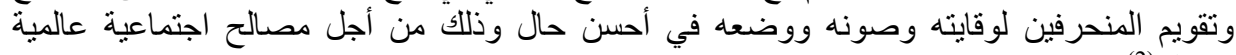

ويعني مفهوم التعاون الدولي تعاون السلطات القضائية في الدول المختلفة لمكافحة الإجرام

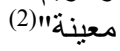

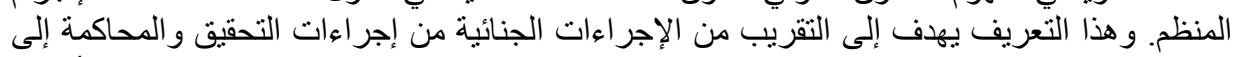

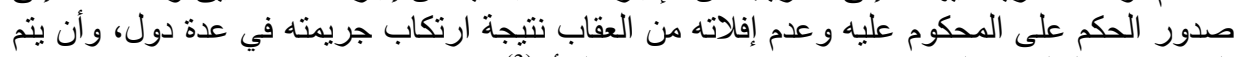

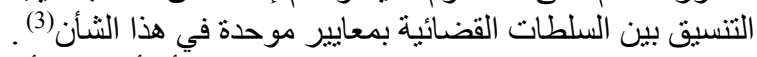

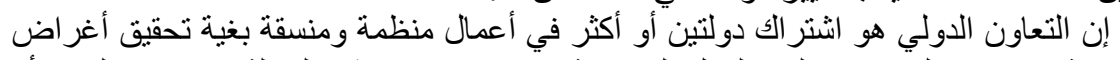

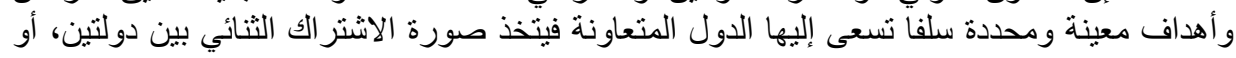


الجماعي بين عدة دول في توحيد إجر اءاتها القضائية كتلك المتعلقة بالأدلة الجنائية أو الإدلاء بالثهادات،

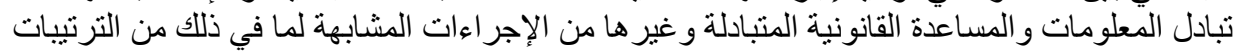

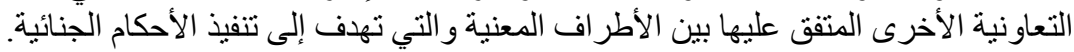

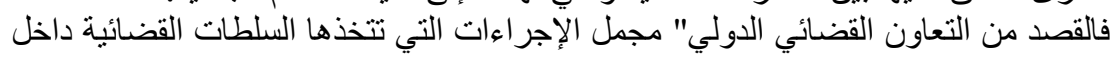

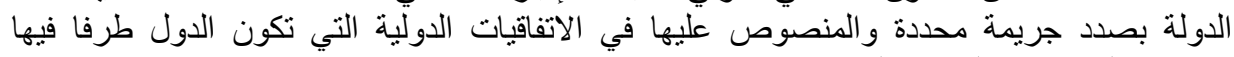
بمقتضى التشريعات الوطنية النافذة". الفقرة الثانية_الطبيعة القانونية للتعاون القانية القضائي الدولي:

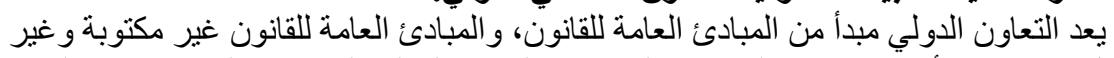

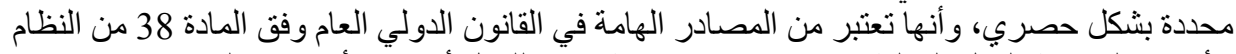

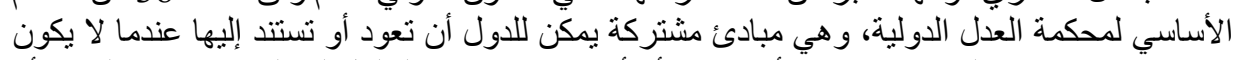

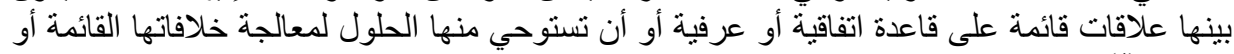

غير أن التعاون القضائي الدولي لا يتقرر بين الدول بالالتز ام العرفي، بل بالالتز ام بالاتفاقيات

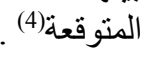

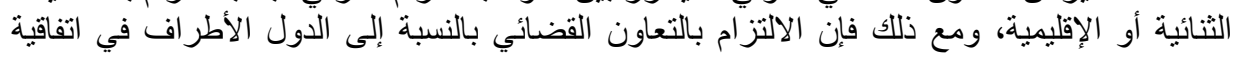

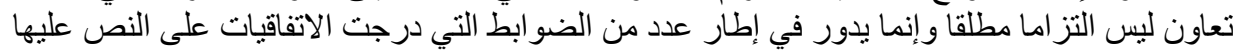

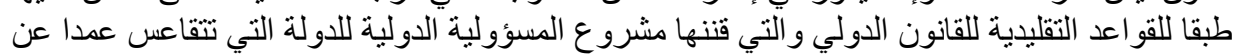

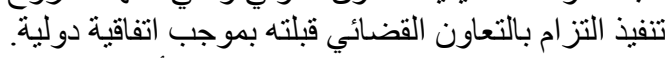

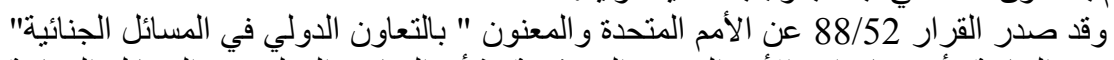

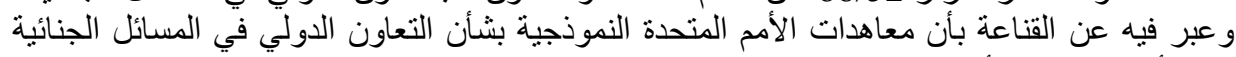

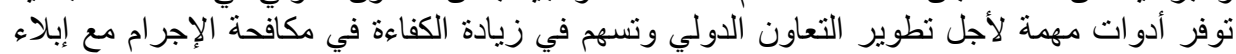

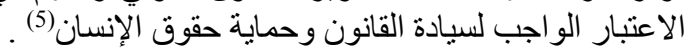

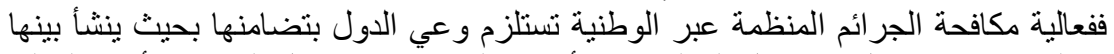

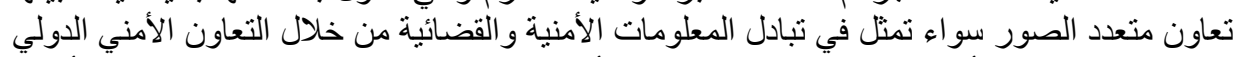

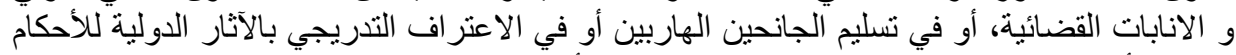

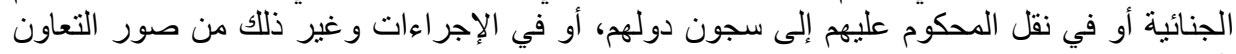

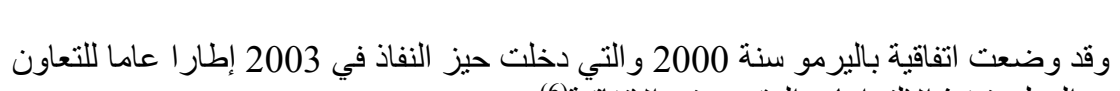
القضائي.

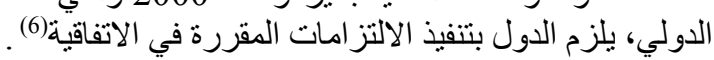

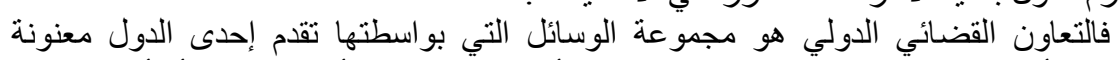

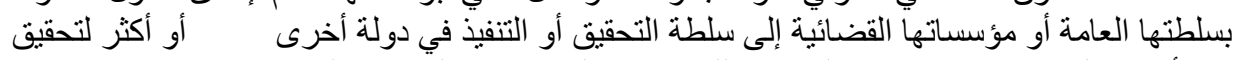

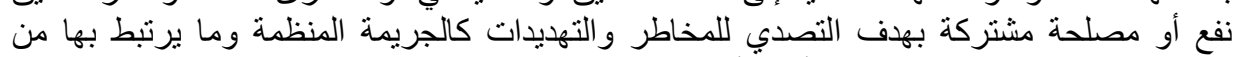

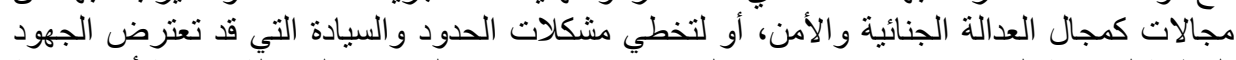

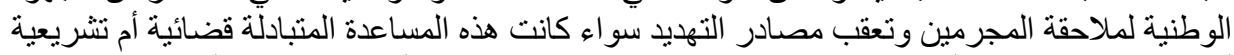

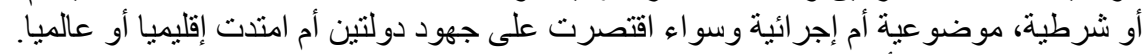

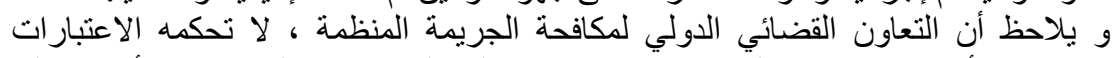

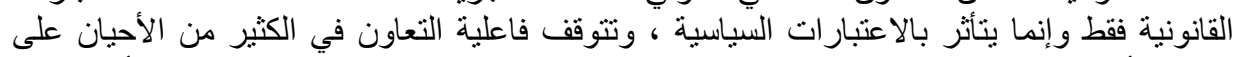

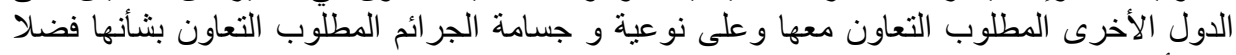

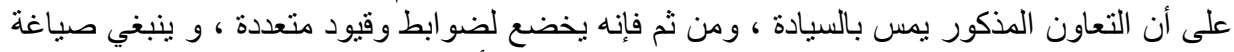

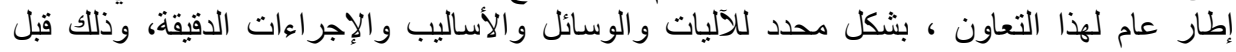

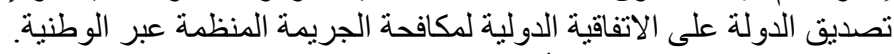

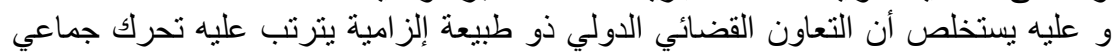

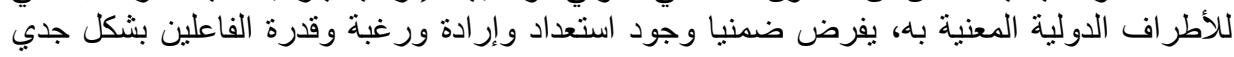


ومنسجم يسهل التدخل في الحياة الاقتصادية والاجتماعية و السياسية للاول المرتبطة بهذا التعاون وهذه

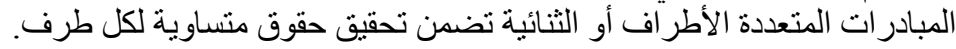
الفرع الثاني: صور التعاون القضائي الاولي:

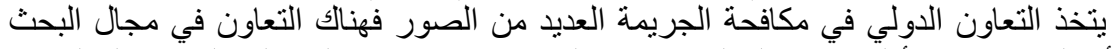

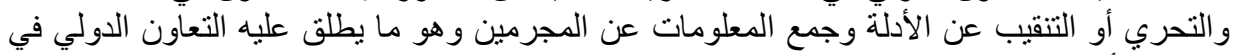

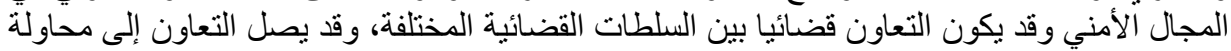
التنسيق أو وحدة القو انين الجنائية المطبقة.

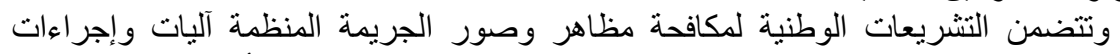

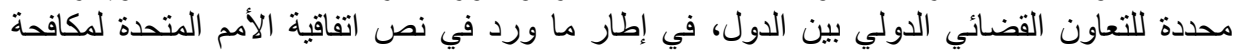

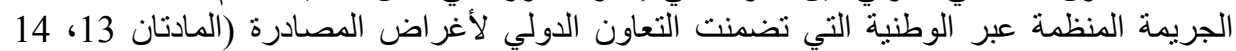

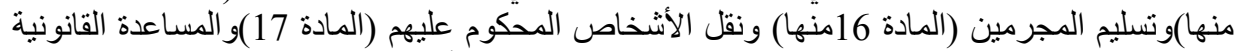

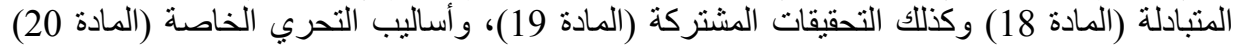

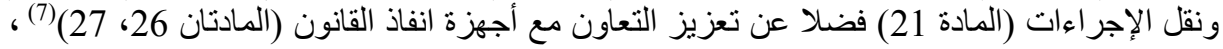

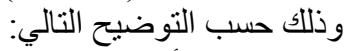

الفقرة الأولى-إجراءات التالت التعاون الدولي في مجال المصادرة:

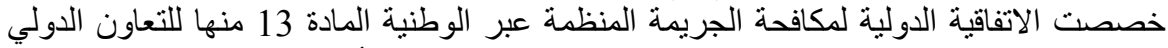

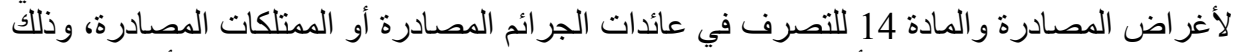

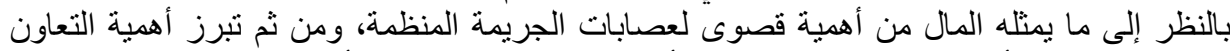

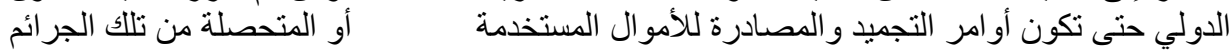

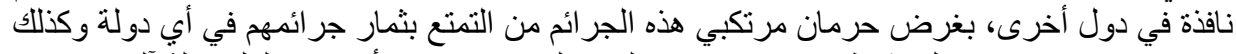

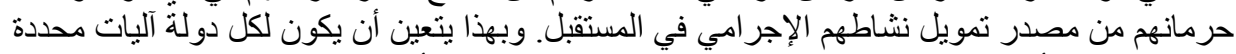

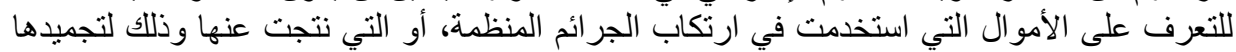

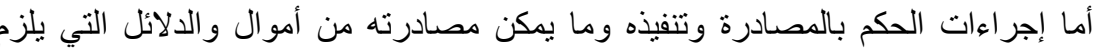

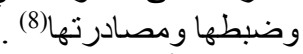

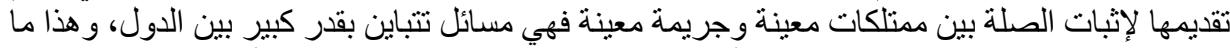

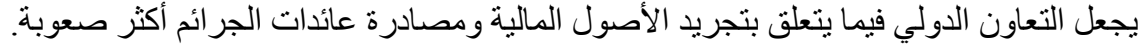

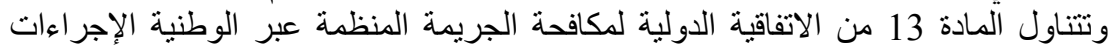

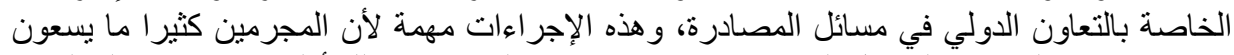

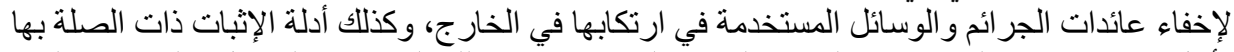

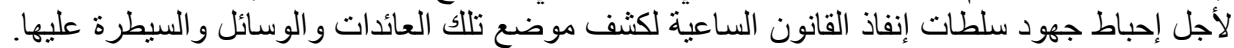
فعلى كل دولة طرف تتلقى طلبا من دولة طرف أخرى أن تتخذ تدابير محددة لتحديد عائدات الجرائ الترائم

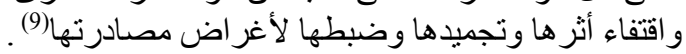

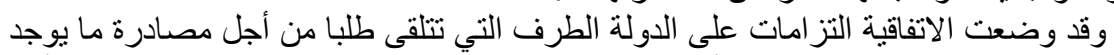

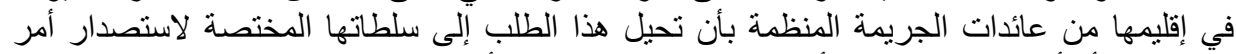

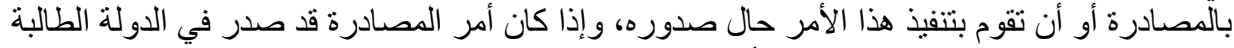

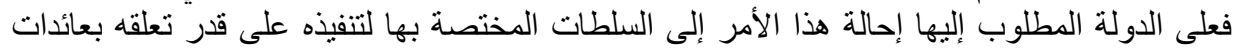
الجر ائم والمتلكات الموجودة في إقليمها.

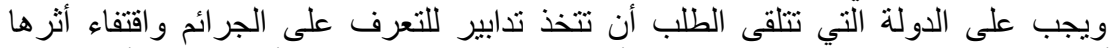
وتجميدها أو ضبطها بغرض مصادرتها، بناء على أمر صادر من الدولة الطالبة أو بناء على أمر صادر التهر من سلطات الدولة المطلوب منها. 
وإن اختارت الدولة الطرف أن تجعل التدابير المطلوب منها اتخاذها مشروطة بوجود معاهدة

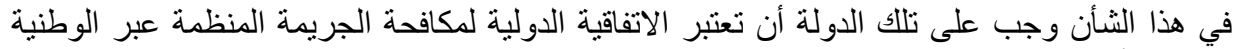

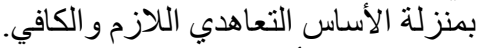

وقد أجازت الفقرة 7 من المادة 13 من الاتفاقية الدولية لمكافحة الجريمة المنظمة المافة عبر الوطنية

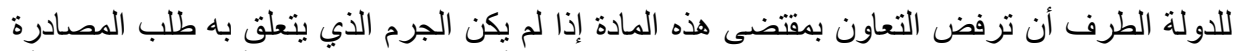

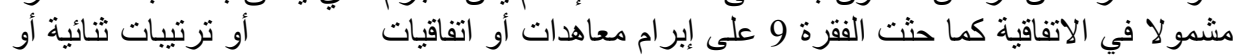

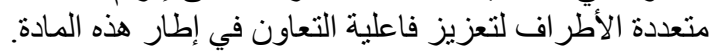

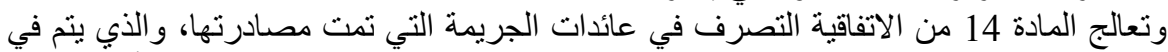

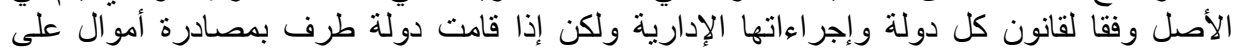

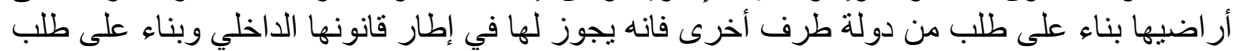

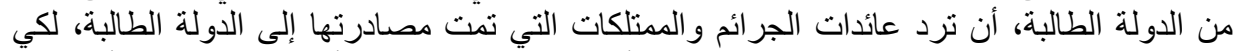

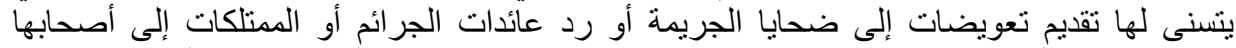

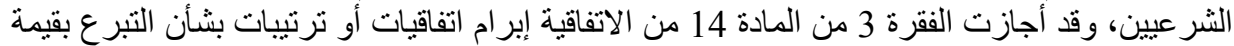

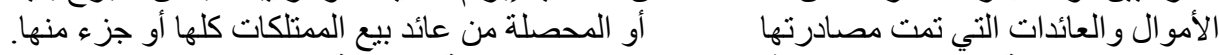

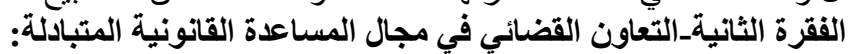

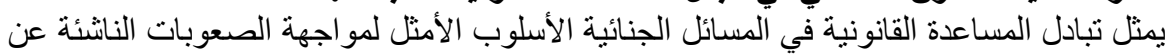

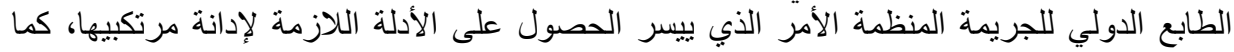

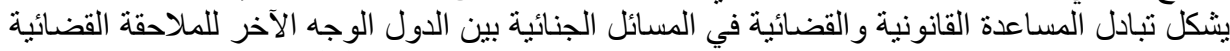

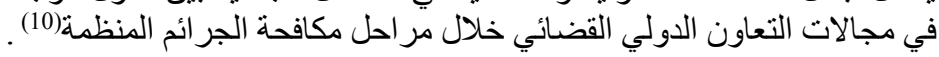

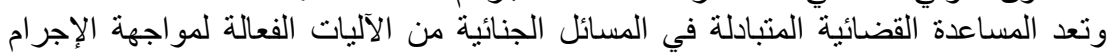

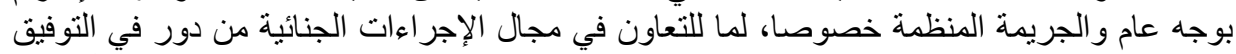

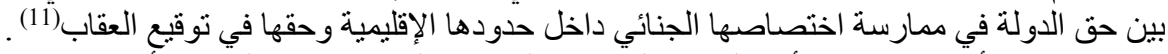

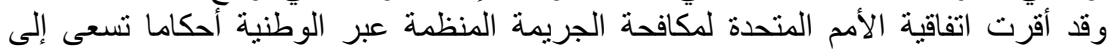

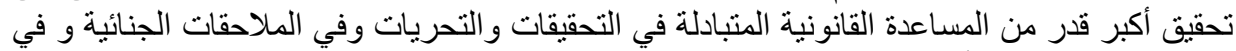

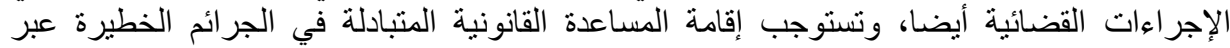

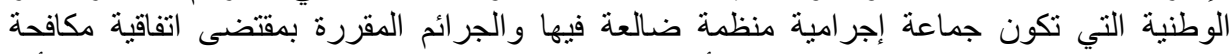

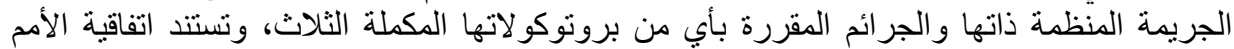

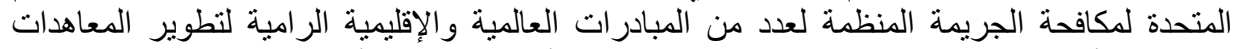

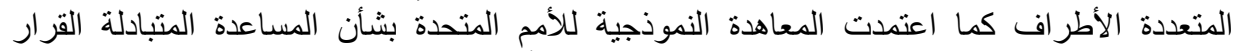

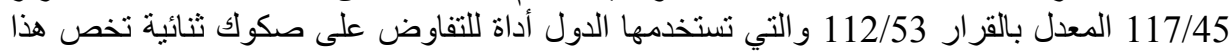

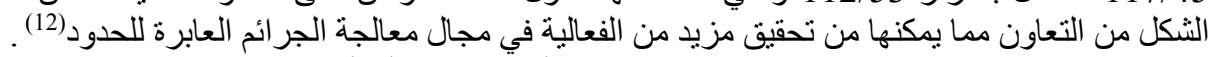

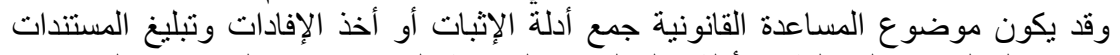

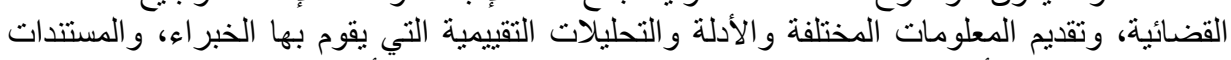

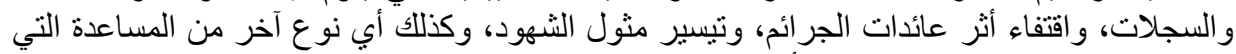

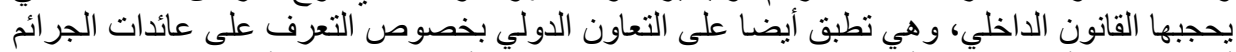

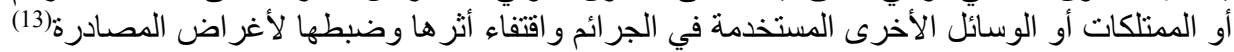

كما أن الاتفاقية تسلم بتتوع النظم القانونية وتجيز بالفعل للاول رفض تضاد تبادل المساعدة القانونية

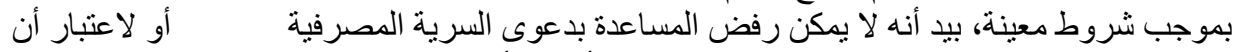

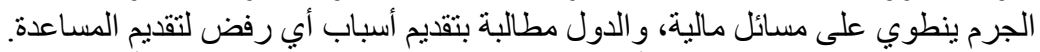

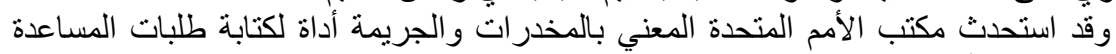

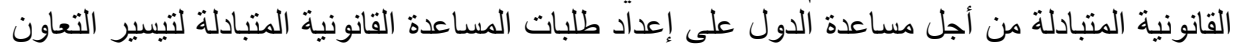




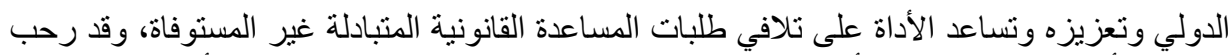

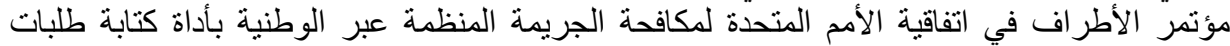

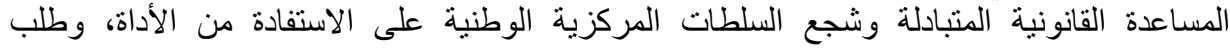

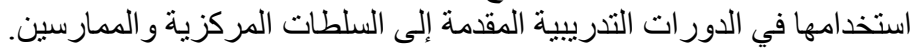
وحددت المادة 18 من الاتفاقية الدذكورة، وعلى سبيل المثال، حالات المساعدة القضائية والتي نذكر من بينها:

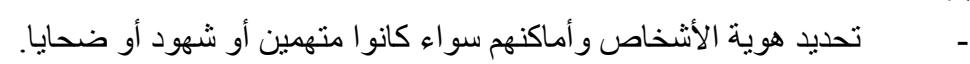
سماع أقو ال الأشخاص سواء كانو ا أشخاص أشاص عاديين أو ضحايا.

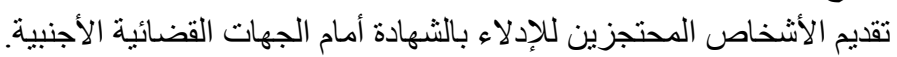

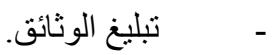

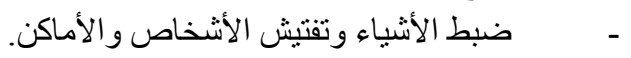

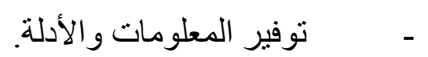

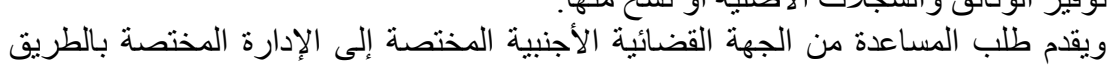

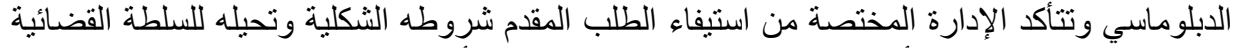

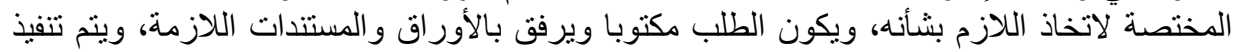

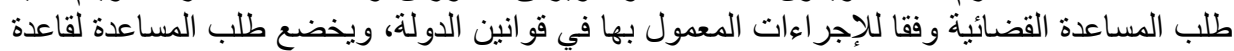
التخصيص فلا يجوز أستخدام المعلومات أو البيانات أو نقلها إلا بصدي التبات التحقيق أو الدحاكمة المحدد في

الفقرة الثالثة_التعاون الدولي بشأن المتهمين والمحكوم عليهم:

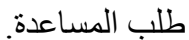

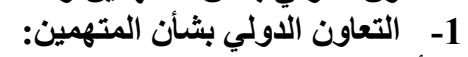

ويتتوع هذا التعاون بين عدة أنظمة منها نظام نقل الإجر اءاتات، وتسليم المجرمين:

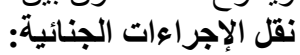

ويقصد بنقل الإجراءات الجنائية أن تقوم دولة بإجراءات تجرئية تجريها فوق أراضيها بمعرفة

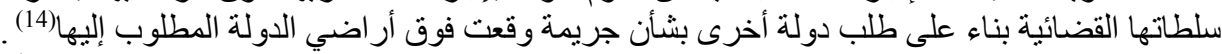

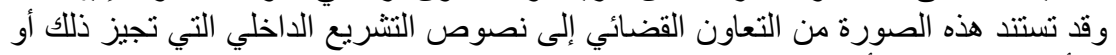

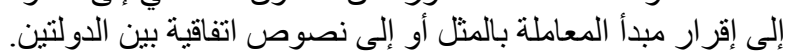

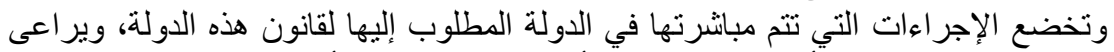

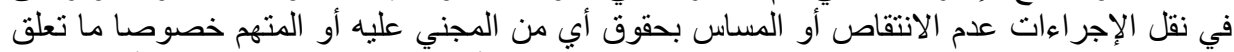

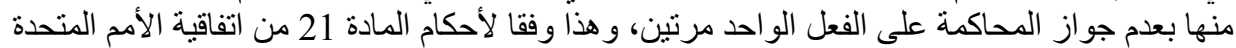

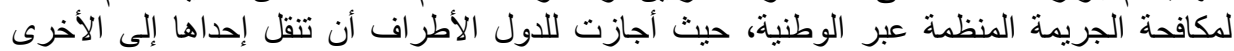

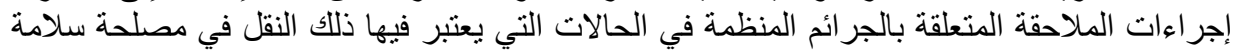

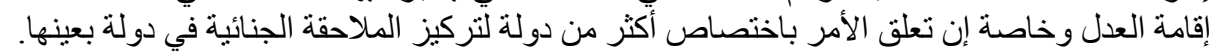

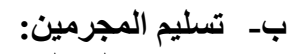

يقصد بتسليم المجرمين أن تتخلى الدولة عن شخص موجود في إقليمها إلى دولة أخرى بناء

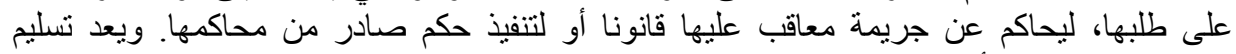

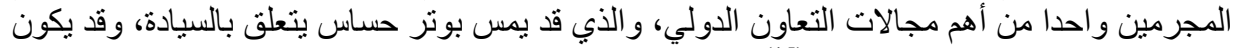
كما يقصد به أيضا مجموعة الإجراءات القانونية التي تهدف إلى قيام دولة بتسليم شخص منهم

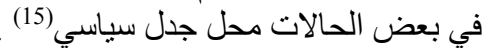

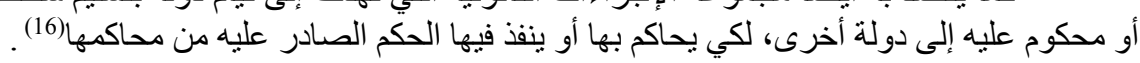


والملاحظ أن اتفاقية الأمم المتحدة لمكافحة الجريمة المنظمة عبر الوطنية اهتمت بتسليم

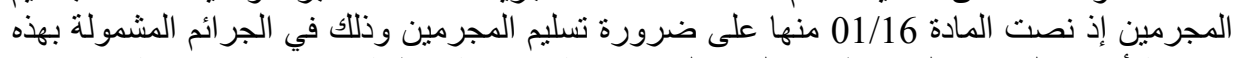

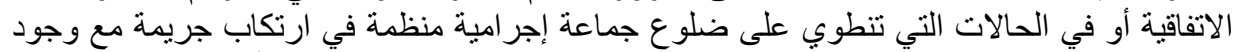

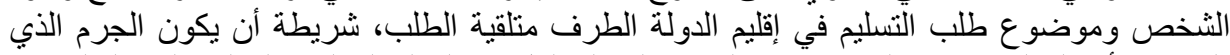
يلتمس بشأنه التسليم معاقبا عليه بمقتضى القانون الداخلي لكل من الدولة الطالبة و الدولة الدئ متلقية الطلب.

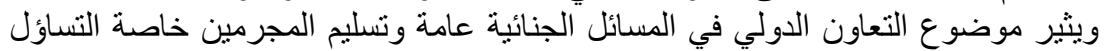

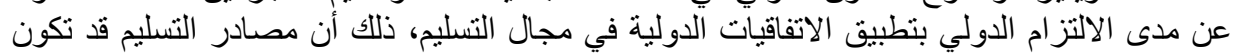

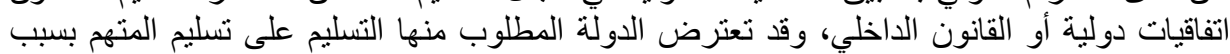

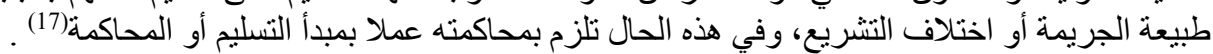

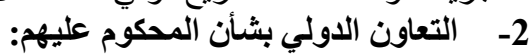

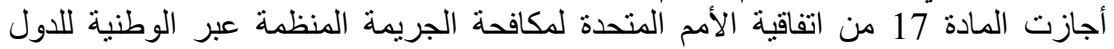

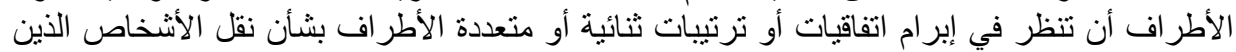

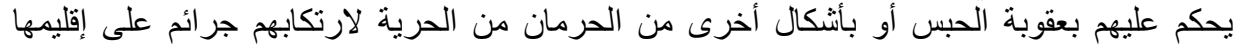
ليتسنى لهم إكمال عقوبتهم هنالك.

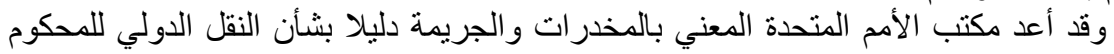

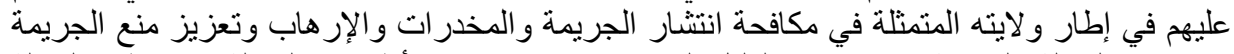

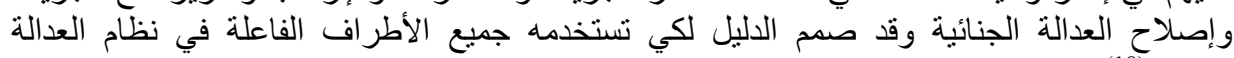

المطلب الثاني: إثكالات التعاون القضائي الدولي لمكافحة الجريمة المنظمة عبر الوطنية

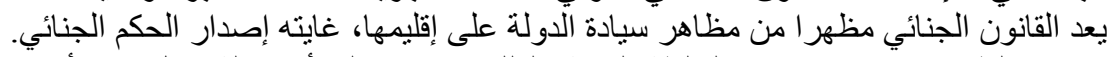

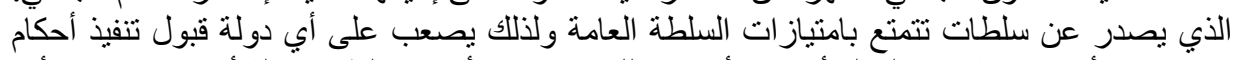

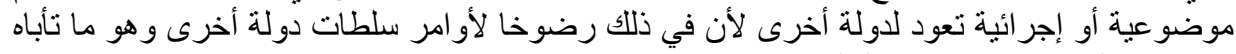
اعتبار ات السيادة في مفهومها أنها التقليدي.

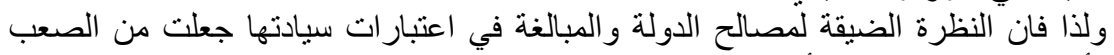

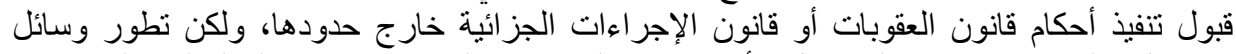

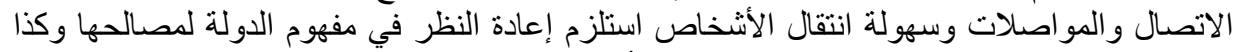

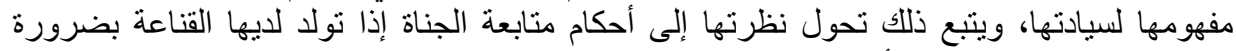

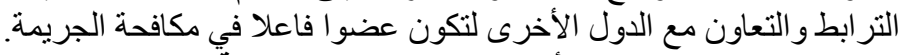

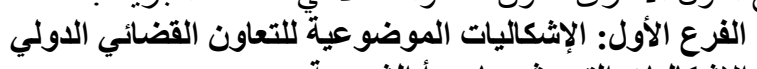

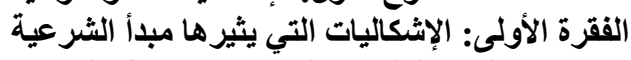

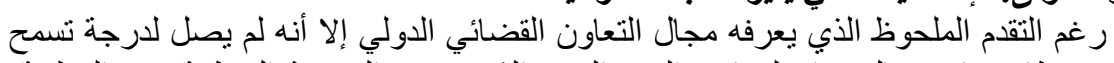

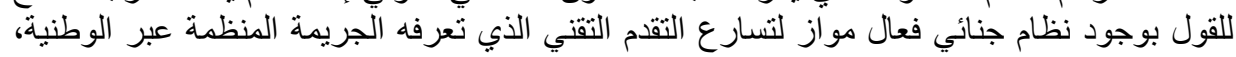

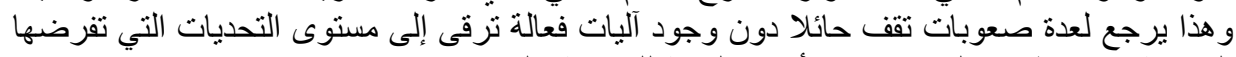

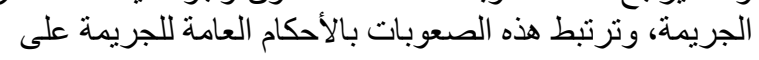

$$
\text { الصعيدين الوطني و الدولي ويمكن ردها إلى ما يلي: }
$$

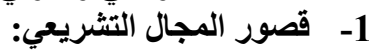

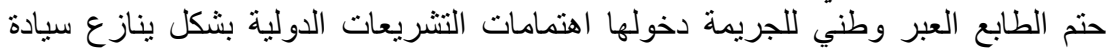

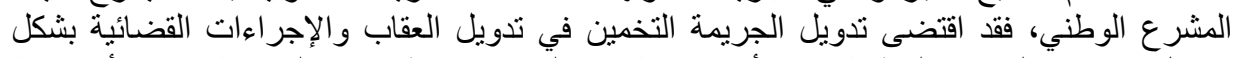

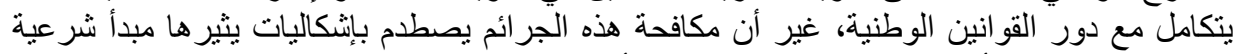

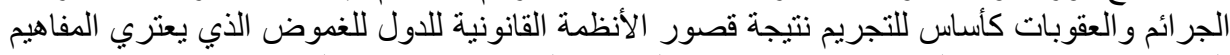

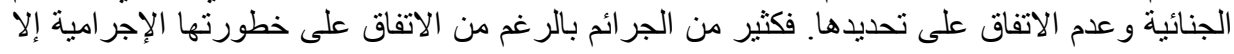


أنها لم تكسب بعد صفة الوضوح و التحديد الذي ينبغي أن يتوافر في الدفاهيم القانونية التي تقرها

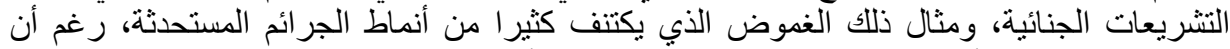

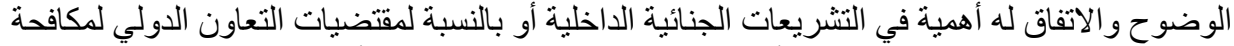

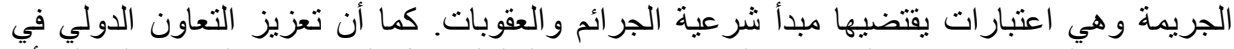

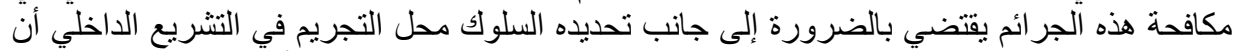

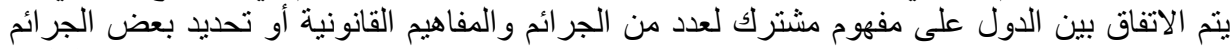

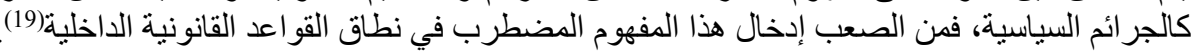
2- 2 التكييف القانوني لبعض الجئ الجرائم:

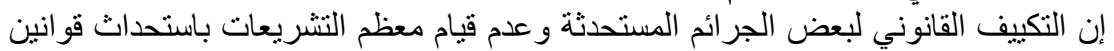

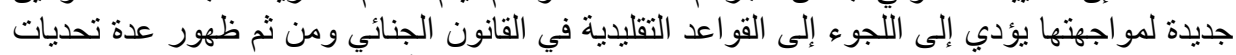

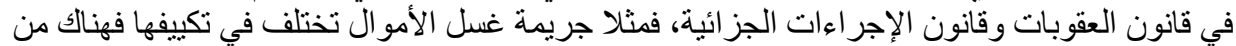

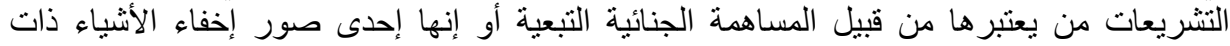

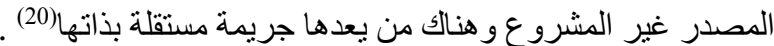

و الأمر كذلك بالنسبة لجرائم الانترنت إذ تعدها بعض الدانئة الدول من جرائم الصحافة باعتبار أن شبكة الانترنت من وسائل النشر. وتلجأ الدول وفي الكثير من الأحيان إلى تطويع النصوص التئل التقليدية على الجرائم المستحدثة،

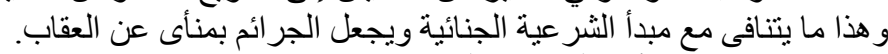
3- 3 ت تعارض الأنظمة القانونية:

تتباين النظم القانونية وتختلف مبادئها، وكذلك العقو بات المقررة للجر ائم كعقوبة الإعدام مثلا

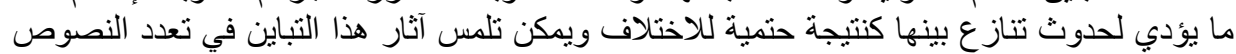

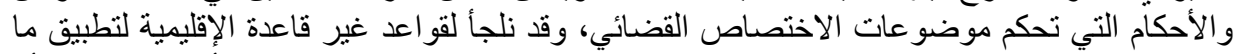

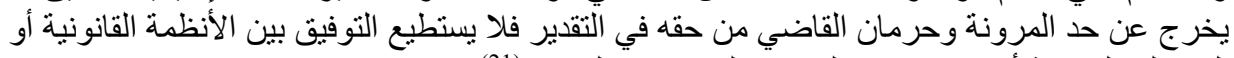

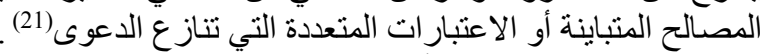

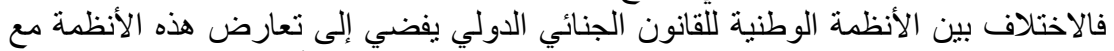

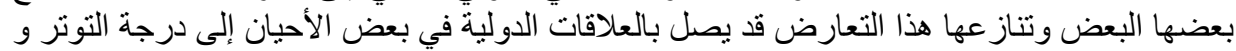

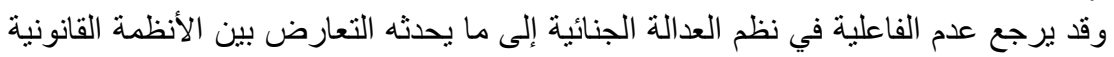
التصادم) (22). (2)

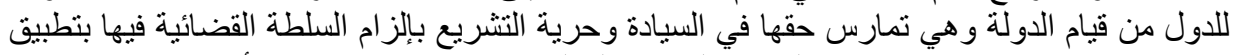

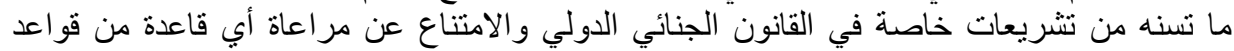

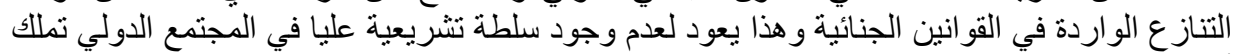

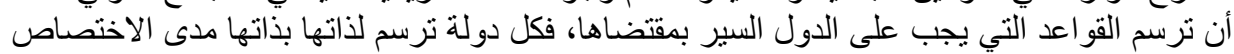

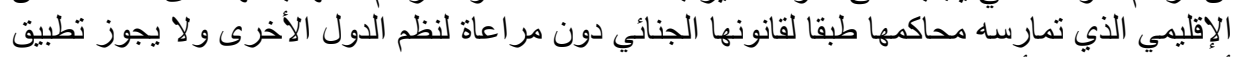

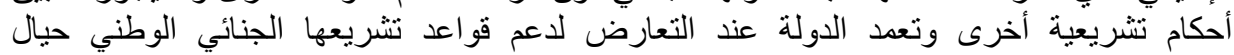

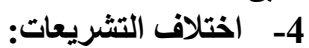

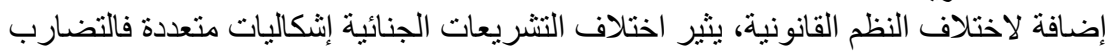

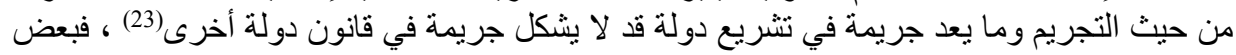

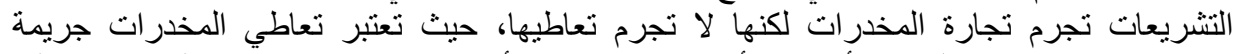

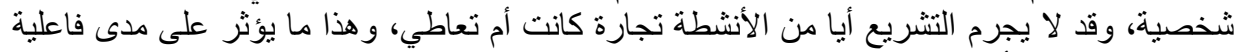

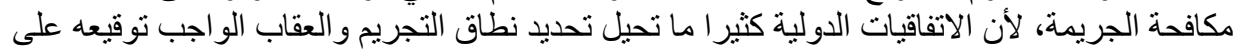

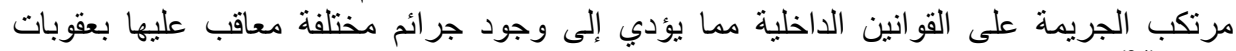

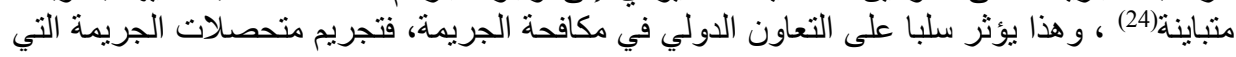


تتم مصادرتها قد يؤثر على حقوق الغير حسن النية فيما يتعلق بإجراءات المصادرة العابرة للحدود،

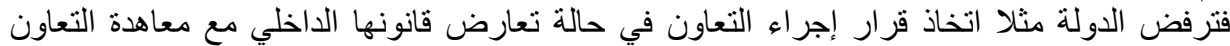

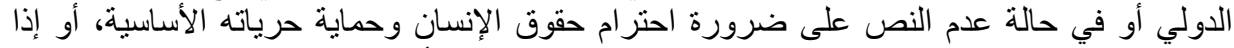

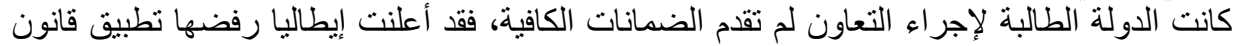

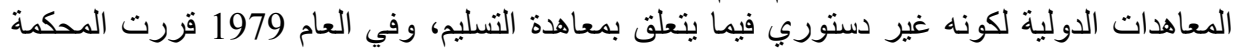

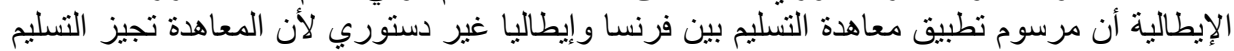

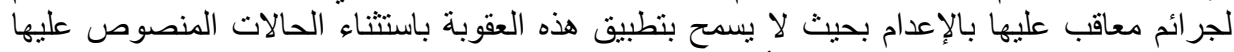

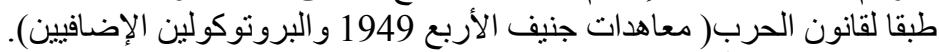

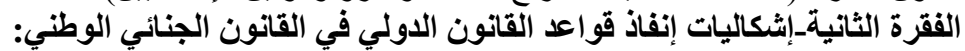

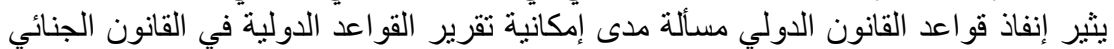

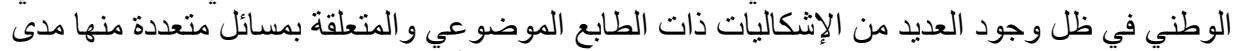

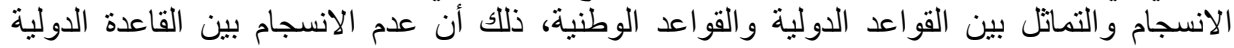

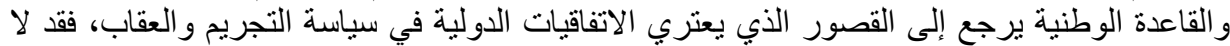

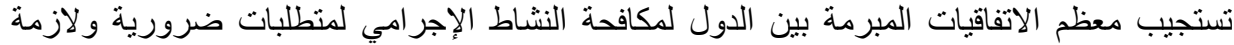

لمكافحة جنائية فعالة.

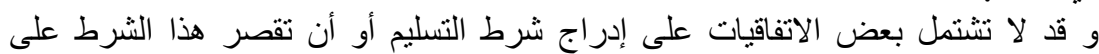

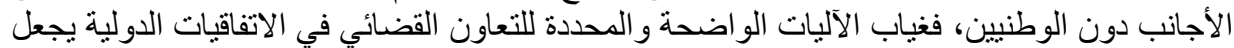

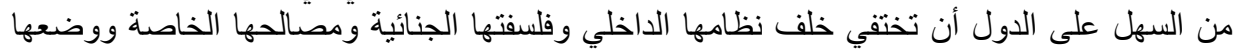
الداخلي وخصوصيات نظامها القانوني (25) .

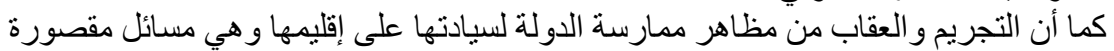

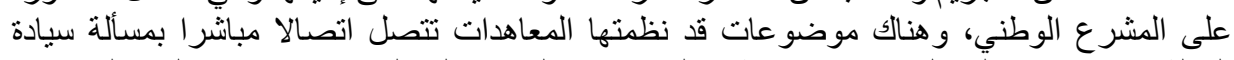

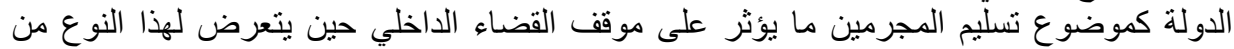

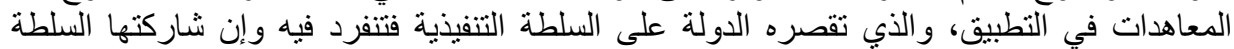

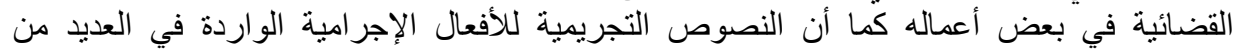

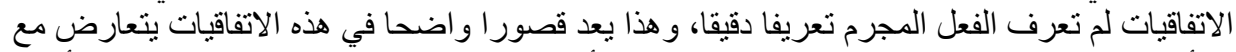

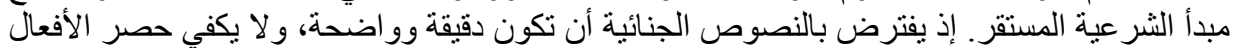

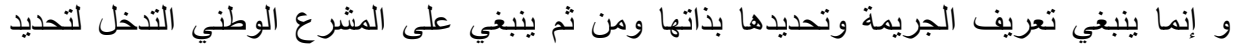
مضمون هذه القاعدة وتحديد العقاب نو عاو ومقدار ا.

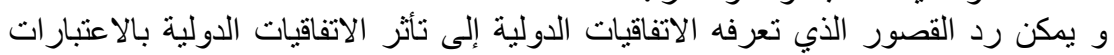

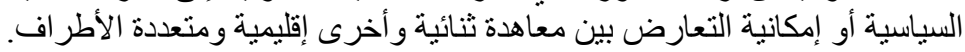

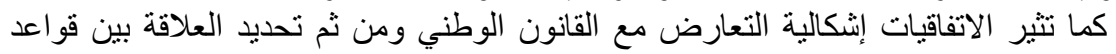

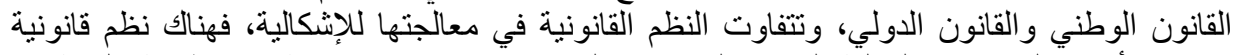

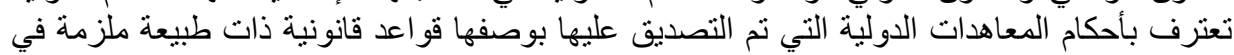

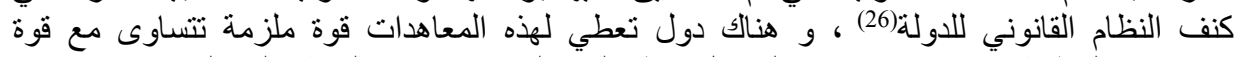

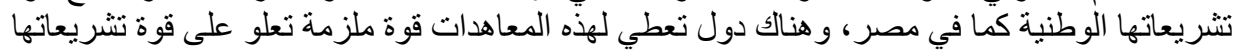
الداخلية كالجز ائر.

ويعود هذا التضارب لمبدأ السيادة الوطنية وما يتفرع عنه من مبدأ عدم جواز التدخل في

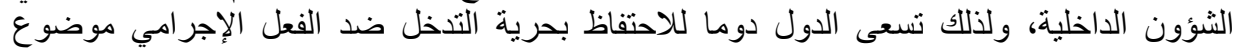

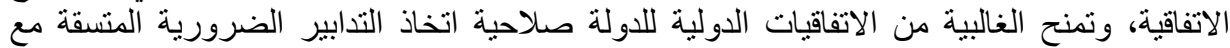

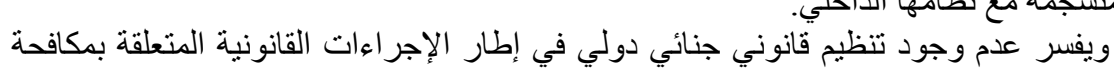
المبادئ المنسجمة مع نظعة الفامها الداخلي.

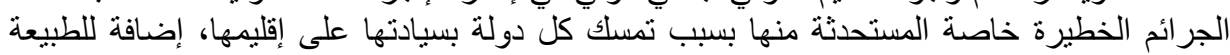


الإلز امية الخاصة لقو اعد القانون الدولي فبالر غم من سمو القانون الدولي فإنه ما يز ال بعيدا عن استيعاب

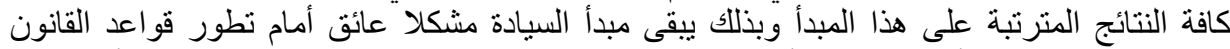

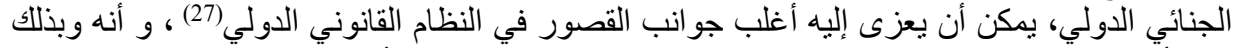

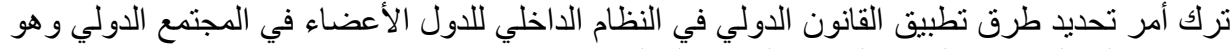
ما يؤثر على الطبيعة الإلز امية لقو اعد القانون الدولئ الإلي.

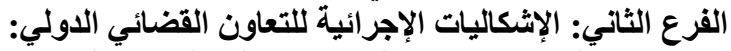

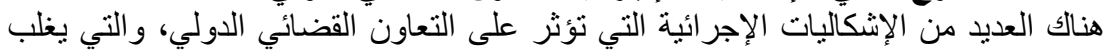

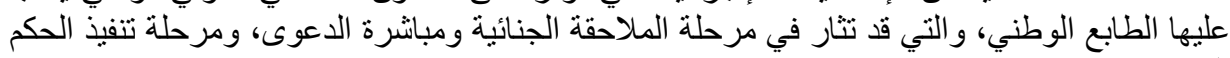

الفقرة الأولى-الإثكاليات التي تعيق التعاون في مرحلة الملاحقة الجنائية:

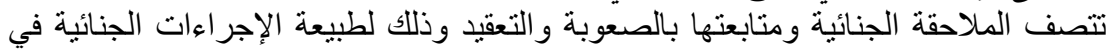

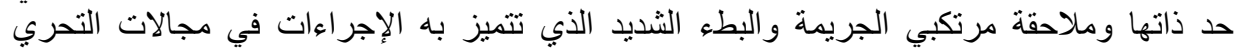

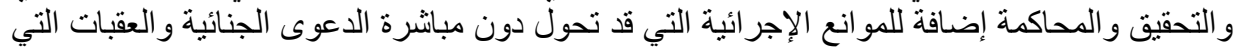

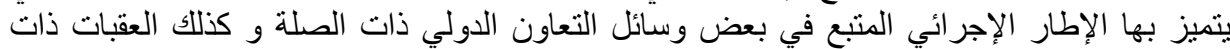
العلاقة بالنظام المالي و الرقابي في المؤسيسات الماتئي المالية.

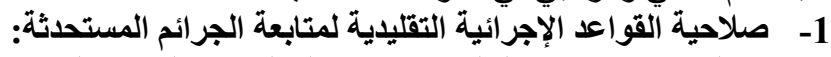

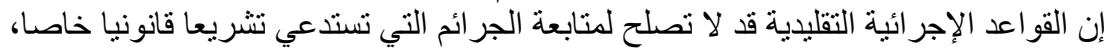

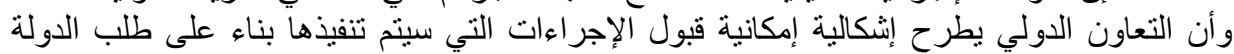

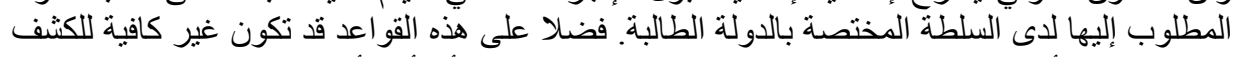

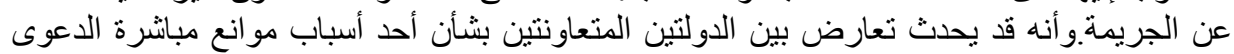

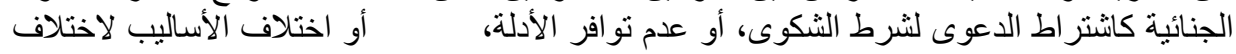

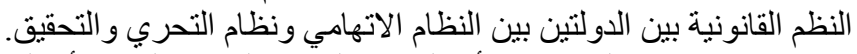

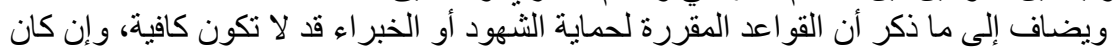

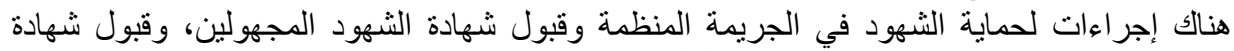
التائبين وتعاو نهم مقابل تخفيف العقاب عليه لجيه (28).

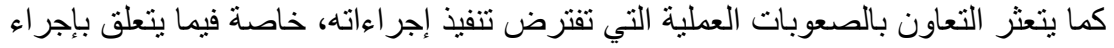

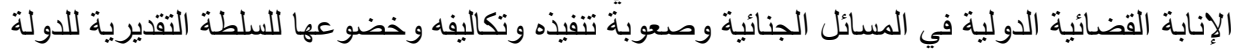

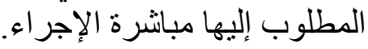

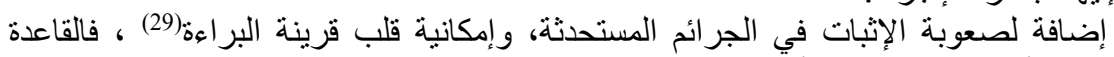

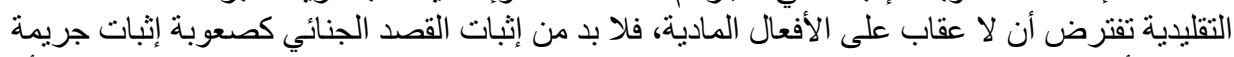

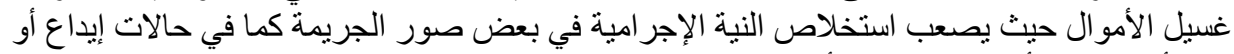

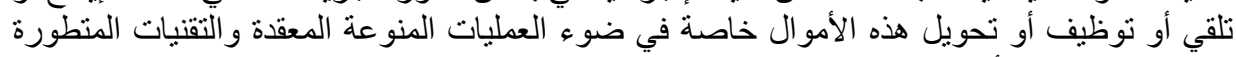

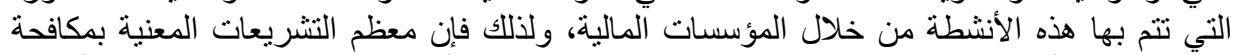

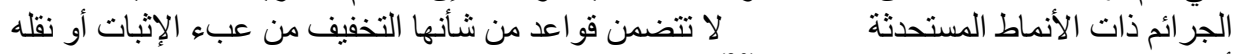

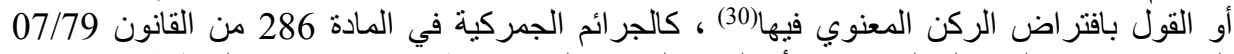

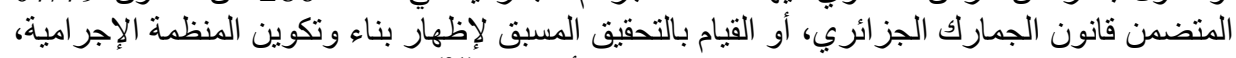

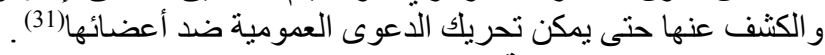
2- 20 إثكاليات متعلقة بطلب التعاون القضائي:

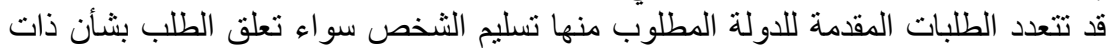

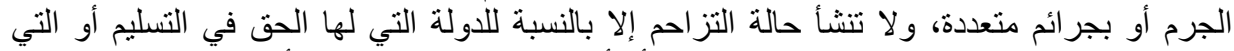

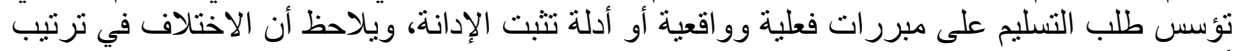
أولويات التسليم في حال التعدد يكون وفقا للمعاهدات وكذللك المصالح السياسية لللدولة. 
ويصعب تحديد الطبيعة القانونية لطلب إجراء التعاون الدولي، من حيث الجهة الجئ المختصة

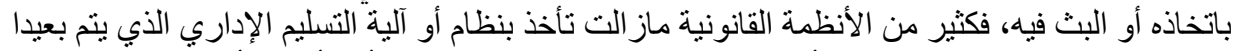

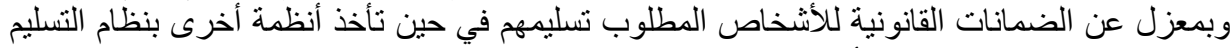

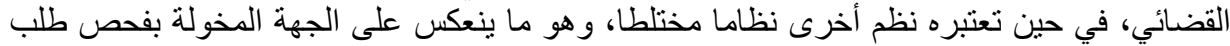

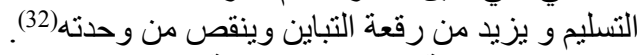

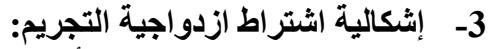

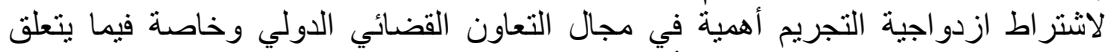

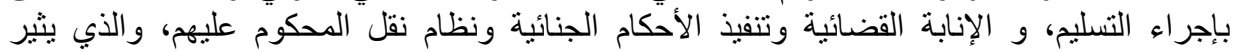

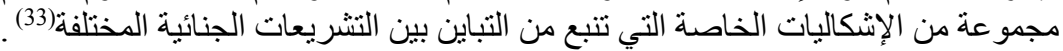

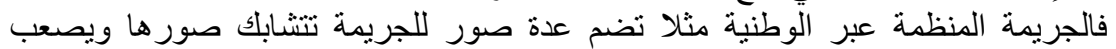

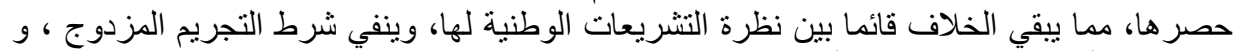

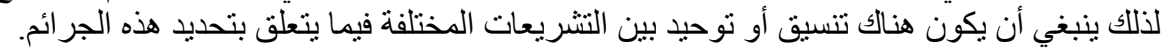

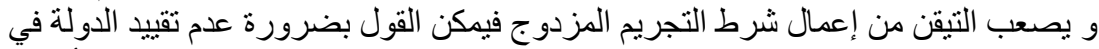

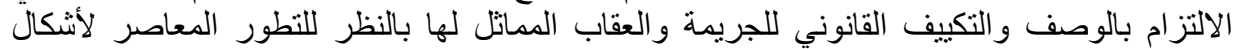
التعاون الدولي وتطور الجئة الجريمة.

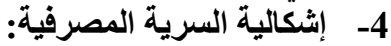

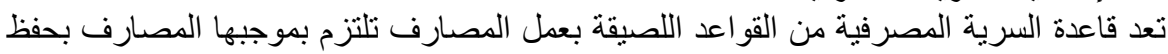

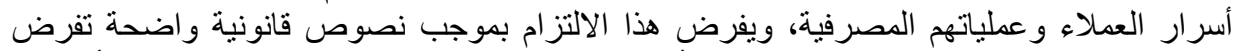

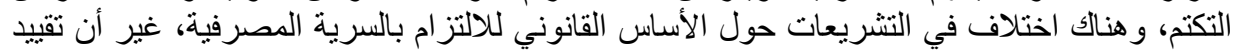

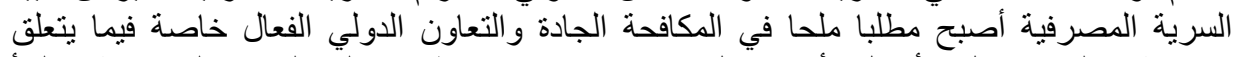

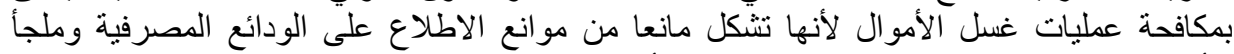

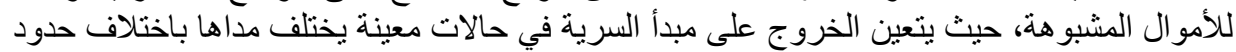

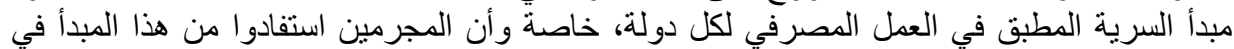

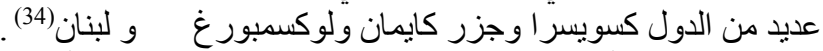

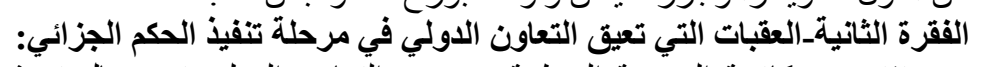

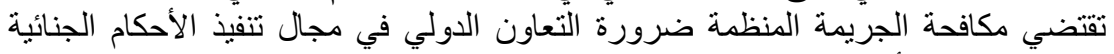

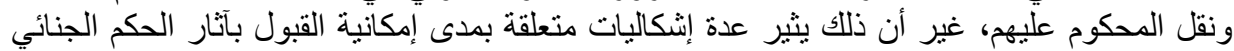

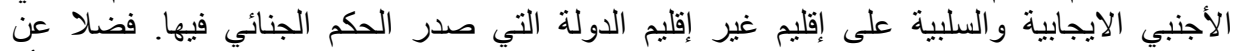

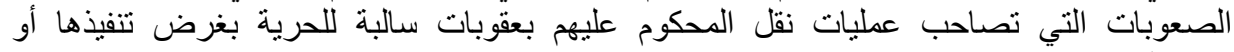

1- 1 إثكالية الاعتراف بالتنفيذ المتبادل للأحكام الجنائية:

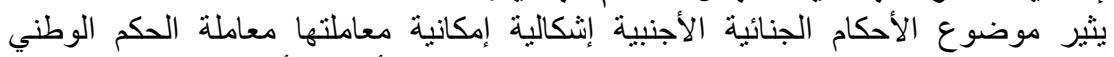

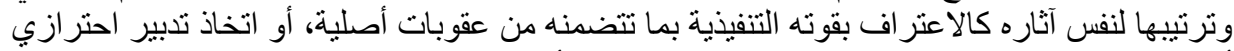

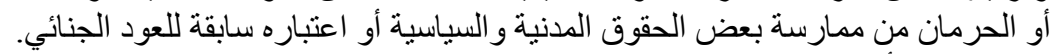

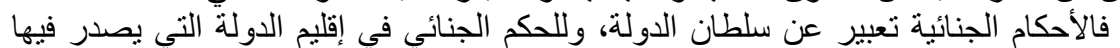

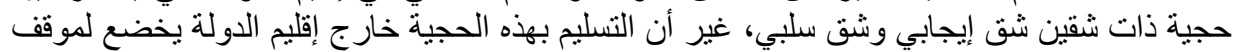

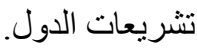

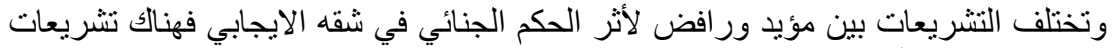

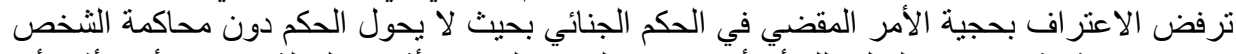

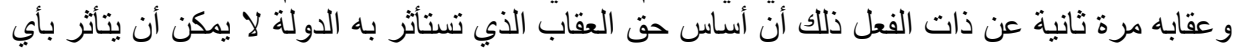
عمل يصدر عن سلطة أجنبية. وتعترف غالبية التشريعات الجنائية بالأثر السلبي للحكم الجنائي الأجنبي لأبي التي 
إعمالا لمبدأ عدم جواز محاكمة الثخص عن فعل واحد مرتين وهذه قاعدة أخلاقية مقررة لتحقيق

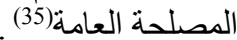

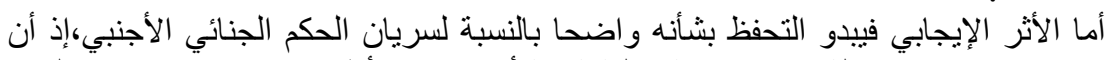

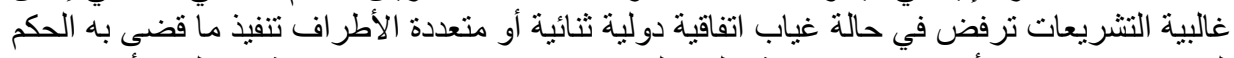

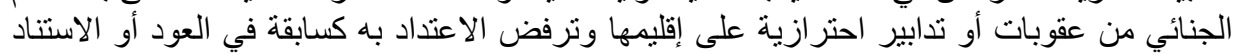

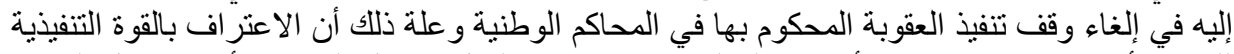

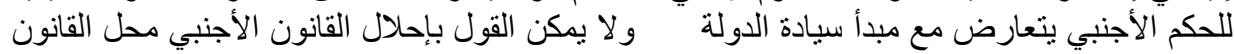

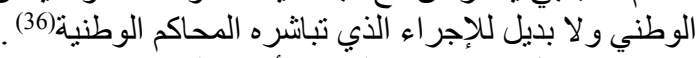

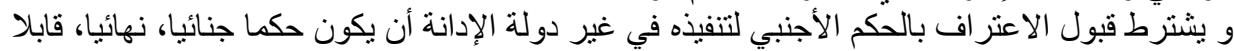

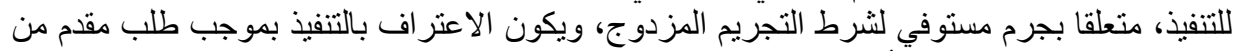

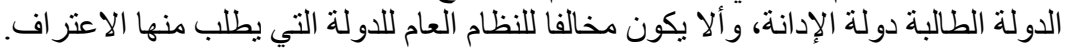
2-2 الإشكاليات المرتبطة بنقل المحكوم عليهم:

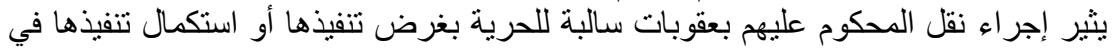

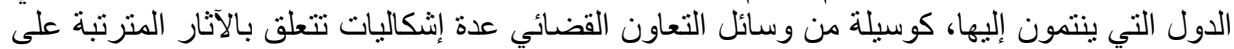

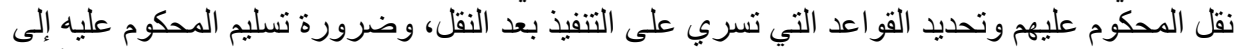

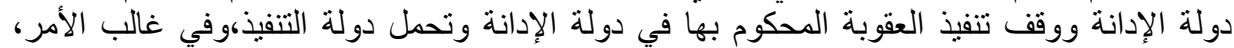
اللمصاريف المترتبة على النقل،ومن ثم تنفيذ العقوبة ل

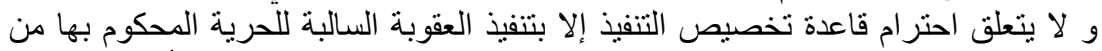

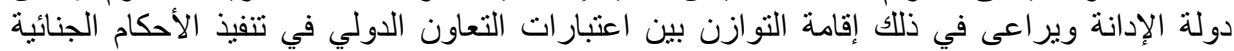

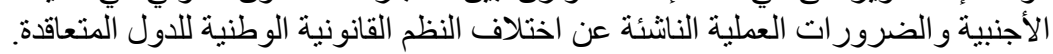

3- 3 إثكاليات تنازع الاختصاص القضائي:

يثير وقوع الأنشطة الإجرامية في أكثر من دولة مشكلة تتعلق بتحديد القانون الواجب التبات التطبيق

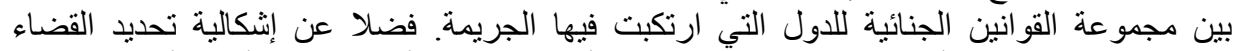

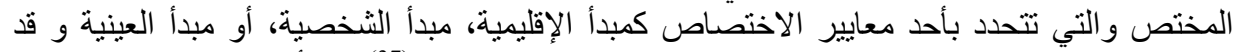

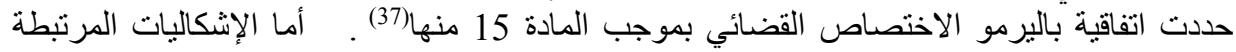

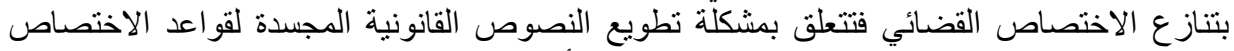

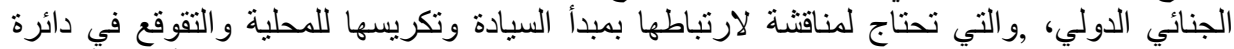

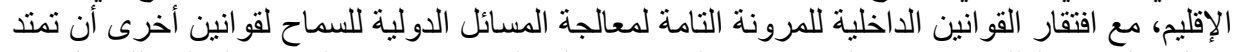

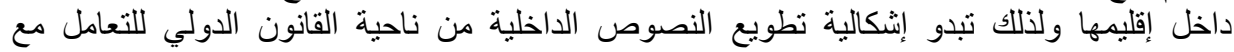

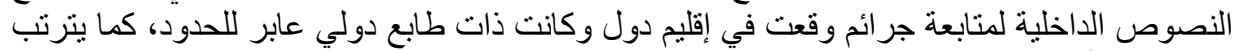

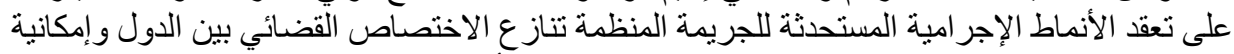

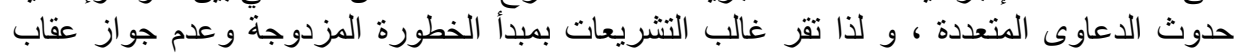

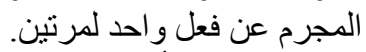

غير أن اختلاف التشريعات في تأسيس اختصاصها القضائي زاد من حالات تنازع

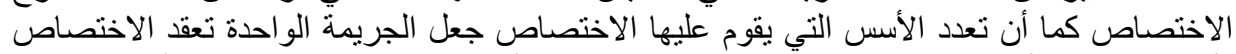

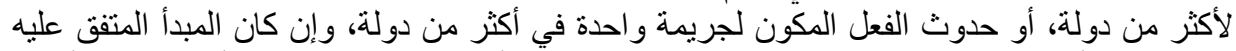

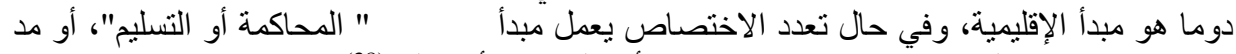

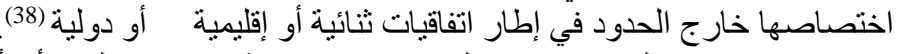

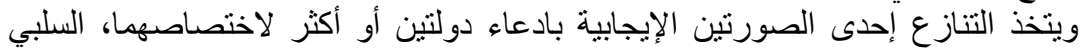

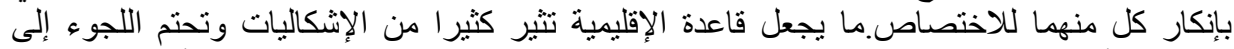

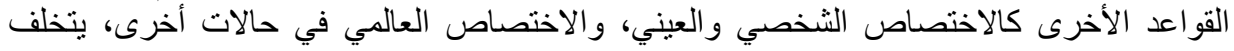


مداها ونطاقها وشمولها باختلاف الدول التي تحل هذه الإشكالية بمر اعاة اعتبار ات متعددة يضاف لها تناقض المصالح و الأنظمة.

فالجريمة الوالحدة يناز عها أكثر من اختصاص والفأ وإن كان البعض يرى أن إعمال مبدأ الإقليمية

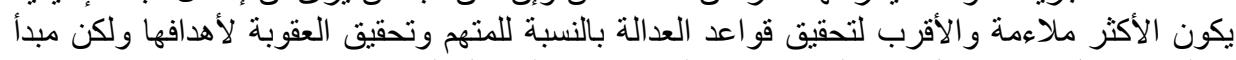

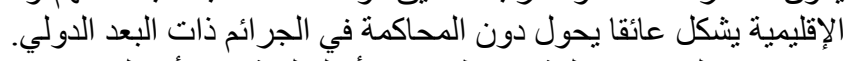

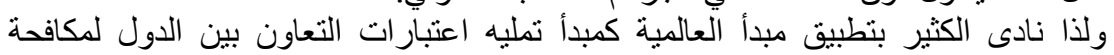

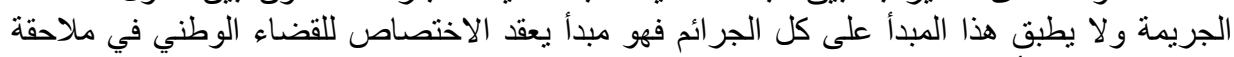

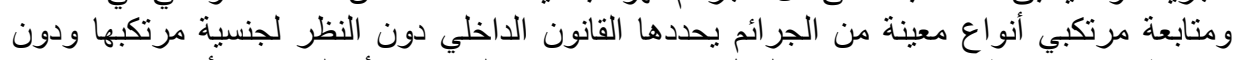

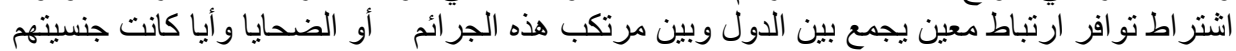
ويسميه البعض بمبدأ "عالمية الحق في العن العقاب".

الخاتمة: و الخداه

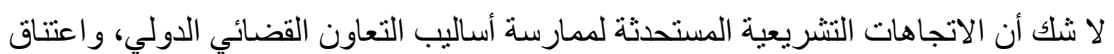

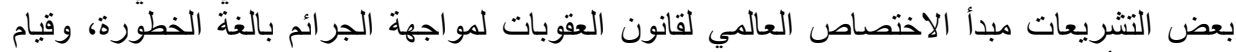

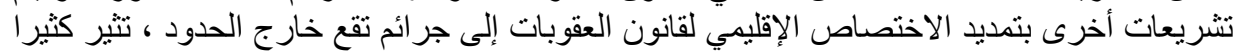

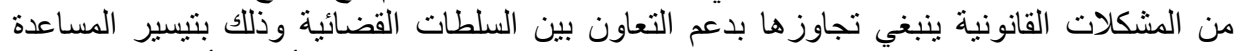

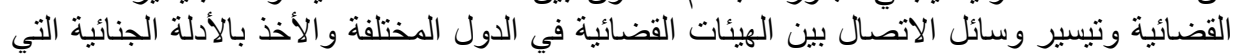

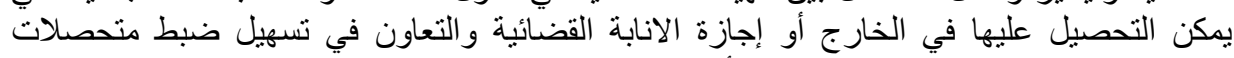

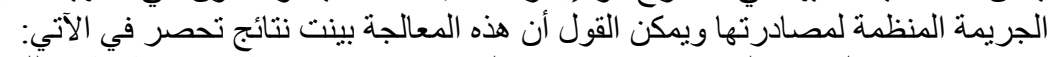

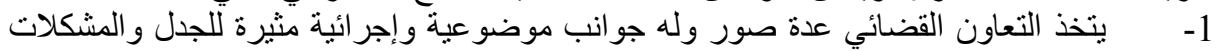

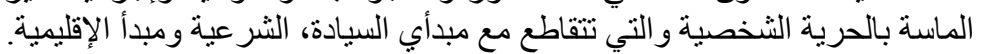

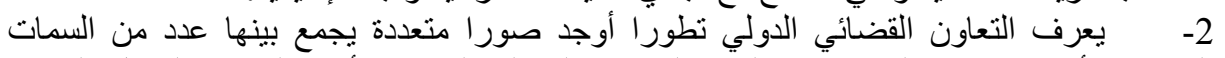
المشتركة أهمها تحقيق التتاغم بين النظم القانونية المختلفة لتوفير الأطر المناسبة لتفعيل التعاون القضائي الدولي.

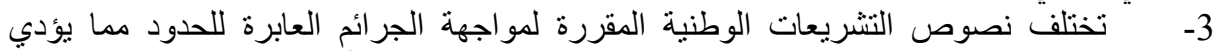

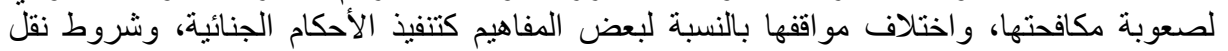
المحكوم عليهم.

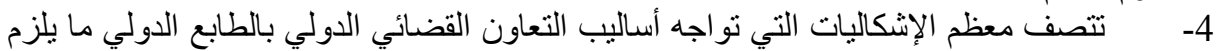

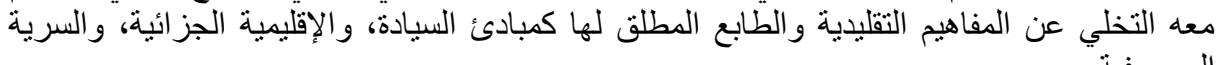

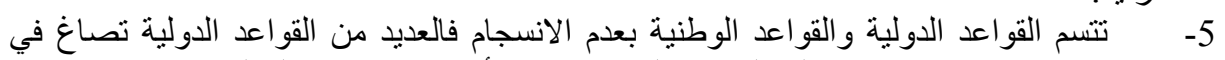
نصوص غامضة مما يتعذر معه على القاضي الوطني تطبيق أحكام الاتفاقيات الدولية.

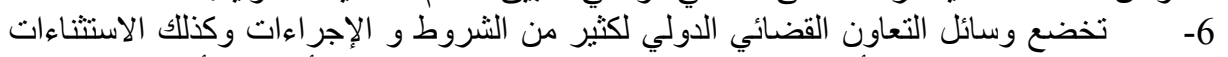

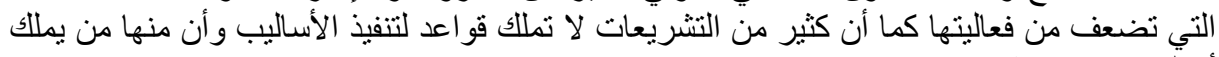
أسالّيب غير كافية. وقد خلصت المعالجة لتوصيات يمكن الأخذ بها لتجاوز إثكاليات التعاون القضائي الدولي:

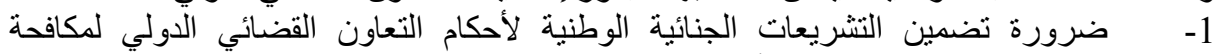

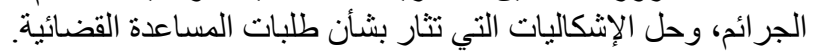

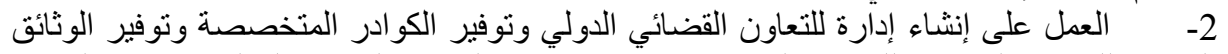
اللازمة للتعاون القضائي للهيئات القضائية، وتعميق وحدة القضاء الجنائي النيائي الدولي بتطوير التعاون 
3- تحديث أساليب التعاون القضائي الدولي واعتماد الأسلوب العلمي واستخدام التقنية الحديثة

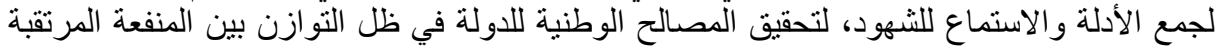

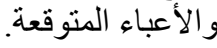

4- التعديل نصوص التنريعات الوطنية وصياغة الاتفاقيات بشكل يتسق مع التطورات الدولية،

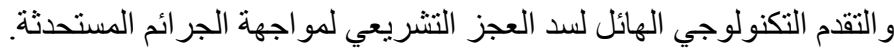

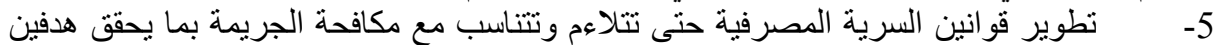

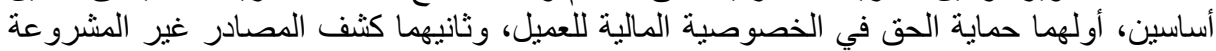

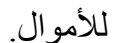

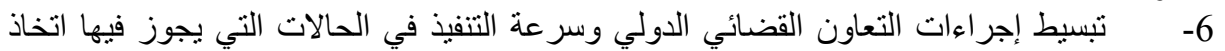

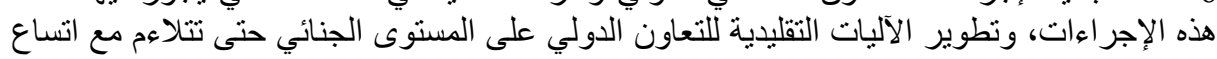

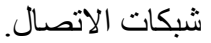

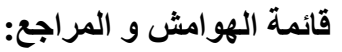

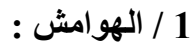

(1)- علاء الدين شحاتة، التعاون الدولي لمكافحة الجريمة، ايترك للنشر و التوزيع، الطبعة 1، مصر،

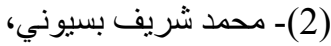

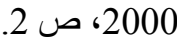
الدخل لدر اسة القانون الجنائي الدولي، مكتبة العهد الدولي العالي للار اسات الجنائية، سير اكوز الئي إيطاليا

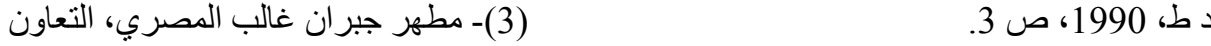

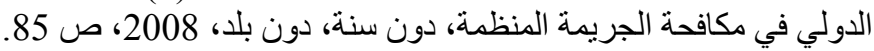
(4)- حنان نايف ملاعب، التعاون الدولي، منشور ات الحلبي الحقوقية، الطبعة الأولى، لبنان، 2015،

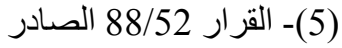

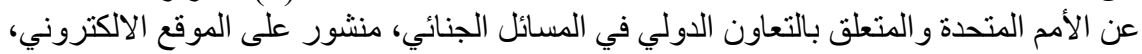
http://www.un.org/arabic/documents/GARes/52/res52088.htm $.2017 / 06 / 17$

(6)- Jean Pradel, la criminalité organisée, Lexis Nexis, Paris 2012 ; p 309. (75)- اتفاقية الأمم المتحدة لمكافحة الجريمة المنظمة عبر الوطنية المعتمدة من قبل الجمعية العامة

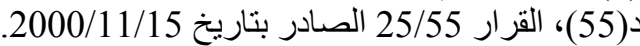

(8)- - محمد سامي الشوا، الجريمة المنظمة وصدارداها على الأنظمة العقابية، دار النهضة العربية،

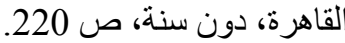
(9)- تقرير مكتب الأمم المتحدة، المعني بالمخدرات والجريمة، البرنامج العالمي لمكافحة الاتجار بالبشر

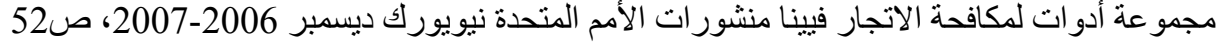

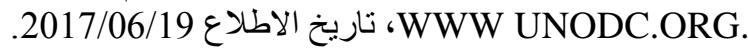

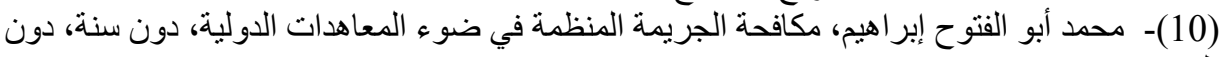

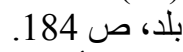

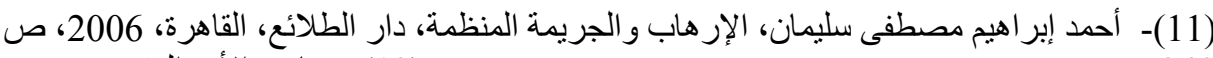
(12) - معاهدة الأمم المتحدة الماند

lega-ad-visory www.unodc.en، النموذجية بشأن المساعدة المتبادلة في المسائل الجنائية،

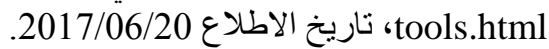

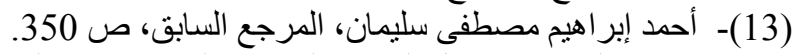

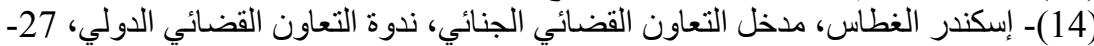

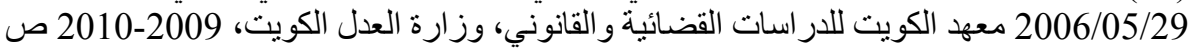




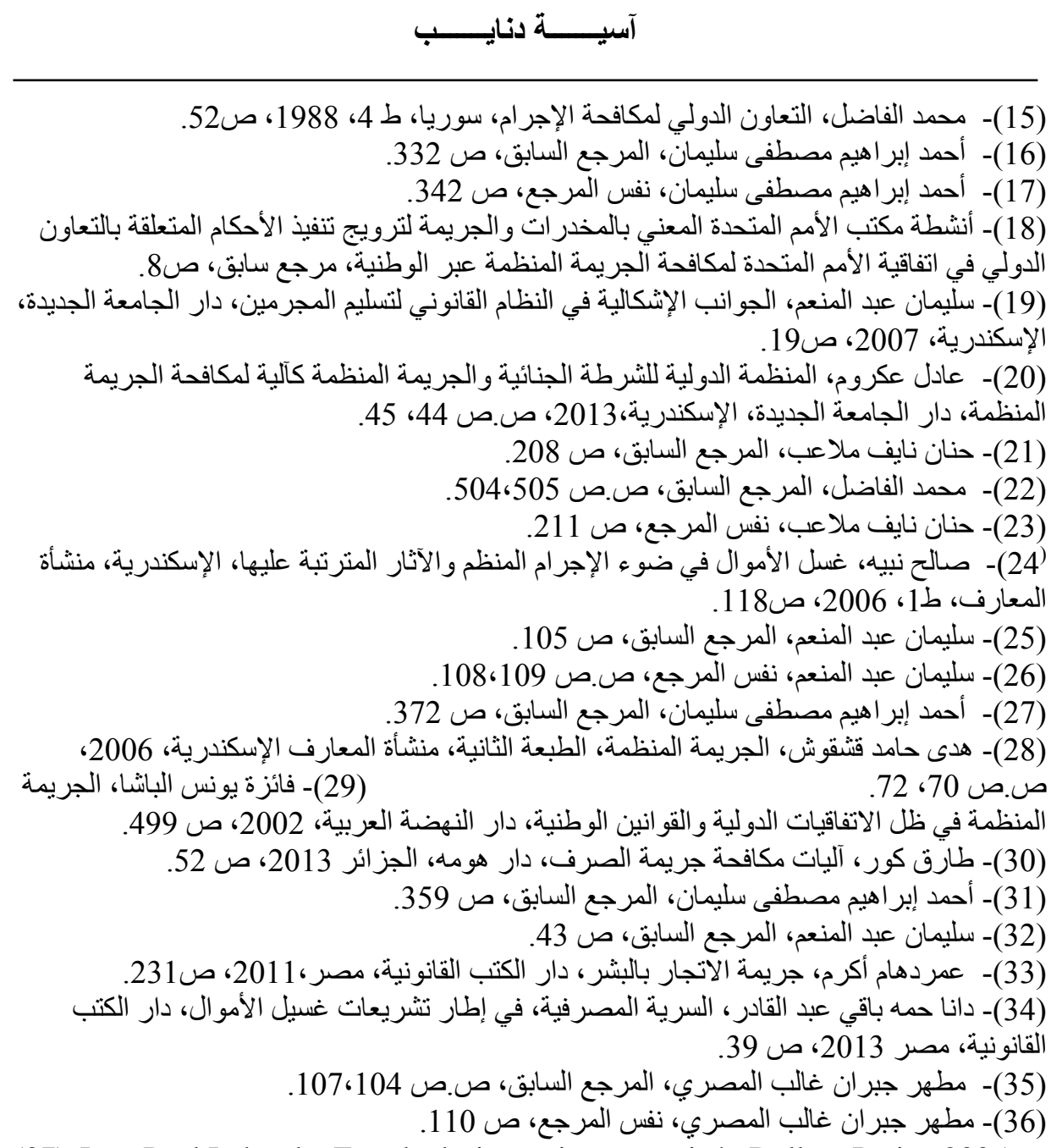

(37)-Jean Paul Laborde; Etat de droit et crime organisé ; Dalloz ;Paris ; 2005 ; P 165.

$$
\text { (38) } 1 \text { ألمراجع : أحمد إبر اهيم مصطفى سليمان، المرجع السابق، ص362. }
$$

1. أحمد ابر اهيم مصطفى سليمان، الإرهاب و الجريمة المنظمة، دار الطلائع، القاهرة، 2006.

2.

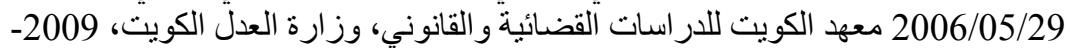

3. -حنان نايف ملاعب، التعاون الدولي، منشور ات الحلبي الحقوقية، الطبعة الأولى، لبنان، 2015

4. دانا حمه باقي عبد القادر، السرية المصرفية، في إطار تنريعات غسيل الأمو ال، دار الكتب القانونية، مصر دئ 2013. 
5. سليمان عبد المنعم، الجو انب الإشكالية في النظام القانوني لتسليم المجرمين، دار الجامعة

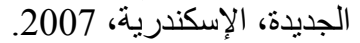

6. صالح نبيه، غسل الأمو ال في ضوء الإجة الإم المنظم و الآثار المترتبة عليها، الإسكندرية،

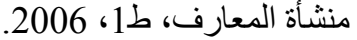

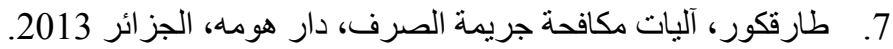

8. عادل عكروم، المنظمة الدولية للثرطة الجنائية المبرة والجريمة المنظمة كآلية لمكافحة الجريمة

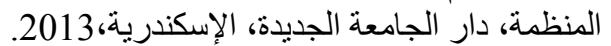

9. علاء الدين شحاتة، التعاون الدولي لمكافحة الجريمة، اليترك للنشر و التوزيع، الطبعة 1، مصر، 2000.

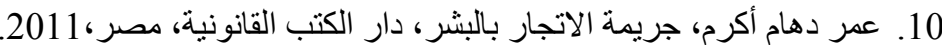
11. فائزة بونس الباثا، الجريمة المنظمة في ظل الاتفاقيات الدولية و القو انين الوطنية، دار النهضة

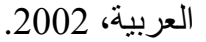

12. محمد أبو الفتوح ابراهيم، مكافحة الجريمة المنظمة في ضوء المعاهدات الدولية، دون سنة، دون بلد.

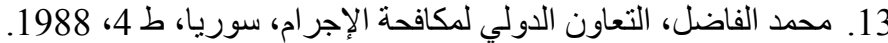

14. محمد سامي الشوا، الجريمة المنظمة وصدارية الفا على الأنظمة العقابية، دار النهضة العربية،

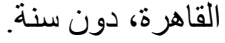
15. محمد شريفبسيوني، الدذخل لدراسة القانون الجنائي الدولي، مكتبة العهد الدولي العالي

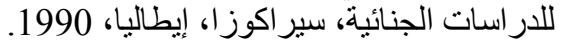
16. مطهر جبران غالب المصري، التعاون الدولي في مكافحة الجريمة المنظمة، دون سنة، دون

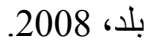

17. هدى حامد قثشقوش، الجريمة المنظمة، الطبعة الثانية، منثأة المعارف الإسكندرية، 2006.

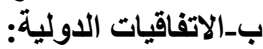

1.اتفاقية الأمم المتحدة لمكافحة الجريمة المنظمة عبر الوطنية المعتمدة من قبل الجمعية العامة

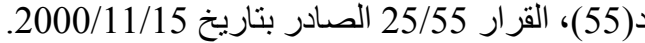
2.0معاهدة الأمم المتحدة النموذجية بشأن المساعدة المتبادلة في المسائل الجنائية،

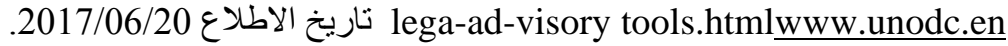
ج-القرارات والتقارير: 1.القرار 88/52 الصنادر عن الأمم المتحدة و المتعلق بالتعاون الدولي في المسائل الجنائي، منشور

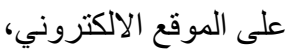
http://www.un.org/arabic/documents/GARes/52/res52088.htm ت التاريخ الاطلاع 2017/06/17.

2.تقرير مكتب الأمم المتحدة، المعني بالمخدرات و الجريمة، البرنامج العالمي لمكافحة الاتجار

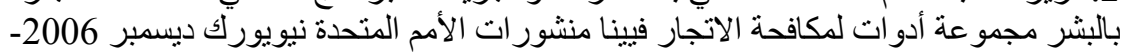

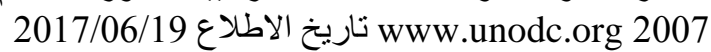
مراجع باللغة الفرنسية:

1. Jean Paul Laborde ; Etat de droit et crime organisé ; Dalloz ; Paris ; 2005 2. JeanPradel, la criminalité organisée, Lexis Nexis, Paris 2012. 